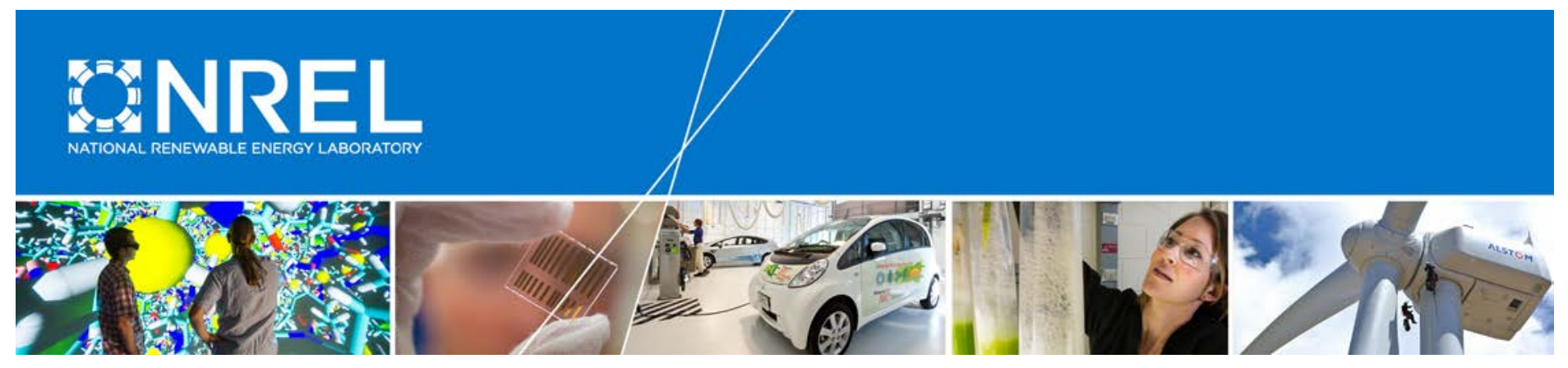

\title{
Grid Ready: Strategies for Interconnecting Large-Scale PV in New York City
}

Tria Case, Shannon Liburd, and Laurie Reilly City University of New York

Kate Anderson, Xiangkun Li, and Lars Lisell National Renewable Energy Laboratory

NREL is a national laboratory of the U.S. Department of Energy Office of Energy Efficiency \& Renewable Energy

Operated by the Alliance for Sustainable Energy, LLC

Technical Report

NREL/TP-7A40-71344

October 2018 


\section{Grid Ready: Strategies for Interconnecting Large-Scale PV in New York City}

Tria Case, Shannon Liburd, and Laurie Reilly City University of New York

Kate Anderson, Xiangkun Li, and Lars Lisell National Renewable Energy Laboratory

NREL is a national laboratory of the U.S. Department of Energy Office of Energy Efficiency \& Renewable Energy

Operated by the Alliance for Sustainable Energy, LLC

National Renewable Energy Laboratory 15013 Denver West Parkway Golden, CO 80401

303-275-3000 • www.nrel.gov
Technical Report

NREL/TP-7A40-71344

October 2018

Contract No. DE-AC36-08G028308 


\section{NOTICE}

This work was authored by the City University of New York and the National Renewable Energy Laboratory, operated by Alliance for Sustainable Energy, LLC, for the U.S. Department of Energy (DOE) under Contract No. DE-AC36-08GO28308. Funding provided by the U.S. Department of Energy Office of Energy Efficiency and Renewable Energy Solar Energy Technologies Office. The views expressed in the article do not necessarily represent the views of the DOE or the U.S. Government.

U.S. Department of Energy (DOE) reports produced after 1991

and a growing number of pre-1991 documents are available

free via www.OSTI.gov.

Cover Photos by Dennis Schroeder: (left to right) NREL 26173, NREL 18302, NREL 19758, NREL 29642, NREL 19795.

NREL prints on paper that contains recycled content. 


\section{Executive Summary}

This Grid Ready Solar project, led by Sustainable CUNY of the City University of New York, is intended to help create transparency for building owners and developers so they can better understand and more quickly navigate the interconnection process for large-scale photovoltaic (PV) projects on Consolidated Edison Company of New York, Inc.'s (Con Edison) electrical grid in New York City (NYC). Phase 1 of the Grid Ready Solar project provided high-level technical screens of grid interconnection requirements in an attempt to streamline the interconnection of large-scale solar PV (200 kilowatts (kW) and larger $\left.{ }^{1}\right)$ systems to the NYC grid. The objective of Phase 2 of this project was to conduct an analysis that would help project developers better understand grid integration strategies, impacts on project costs, and solutions that can be implemented to install solar on buildings with PV potential. This analysis could provide an analytical framework for incorporation into the long-term planning efforts of other utilities that operate network grids. In Phase 2, Sustainable CUNY worked with the National Renewable Energy Laboratory (NREL) to evaluate a range of solutions for improving the economics of large-scale PV within the five boroughs of New York City that are in Con Edison's service territory, as identified on the NY Solar Map. $^{2}$

To determine appropriate ways to improve the economic feasibility of large-scale solar PV interconnection at the building level, Sustainable CUNY contracted analysts from NREL to assess suitable short-term and long-term mitigation strategies using REopt. ${ }^{3}$ The results of the Phase 2 analysis show that energy storage is the most cost-effective solution for reducing interconnection costs. Using energy storage to limit or eliminate energy export from a PV system actually improves project economics over the base case of installing standalone PV under all rate classes evaluated in this study. The economics of energy storage in New York City is sufficiently favorable that adding storage lowered the total project life cycle cost thereby offsetting the higher capital costs associated with initially adding storage to the PV system.

As part of New York State's Reforming the Energy Vision (REV), New York State is transitioning away from net energy metering (NEM) and toward developing a more precise approach to valuing distributed energy resources (VDER). NEM is a volumetric metering method that applies a kilowatt-hour (kWh) credit to a customer's utility bill for PV production exported to the grid. VDER considers the time and location of the generation in its compensation structure and converts energy production into dollars (e.g., PV customers see a dollar credit on their energy bill). For both metering methods, solar PV-generated electricity consumed on-site is not credited but reduces the customer's bill as energy efficiency would. The Phase 2 Grid Ready analysis quantifies the impacts of the export mitigation strategies and system economics as NYC moves from NEM to VDER. The results of an NREL REopt analysis show that VDER will lower revenue for PV system owners of large (>10 kW) residential and commercial buildings when compared against

\footnotetext{
${ }^{1}$ Denotation of commercial and industrial solar PV systems as larger than $200 \mathrm{~kW}$ is based on Megawatt Block Dashboards. https://www.nyserda.ny.gov/All-Programs/Programs/NY-Sun/Megawatt-Block-Dashboards

${ }^{2}$ The New York Solar Map is a map platform that can be used to quickly perform solar analysis on sites in New York State. The map also hosts resources for solar in New York State. https://www.nysolarmap.com/

${ }^{3}$ REopt is a techno-economic decision support model developed by NREL to optimize energy systems for buildings, campuses, communities, and microgrids. For more information, see https://reopt.nrel.gov/.
} 
the current NEM compensation structure, but reductions are on the order of less than $1 \%$. This implies that financial compensation for solar energy exports to the grid from buildings that can accommodate large-scale ( $>200 \mathrm{~kW}$ ) solar PV systems would not be significantly impacted by NYC switching from NEM to VDER. Additional studies are needed to understand the impact of VDER relative to NEM on smaller buildings with exports of less than $200 \mathrm{~kW}$ of solar to the grid.

The VDER value stack consists of several elements representing the value of clean energy to the grid and the environment. The installed capacity (ICAP) component of the value stack mirrors the capacity credit currently provided under NEM $(\$ / \mathrm{kWh})$. There are two ICAP alternatives for PV-only systems: Alternative 1 , which is spread across all hours of the year and Alternative 2 , which is concentrated over 460 summer ${ }^{4}$ hours. Dispatchable resources, such as PV paired with storage, are only eligible for ICAP Alterative $3^{5}$ and is credited based on the coincident grid peak $(\$ / \mathrm{kW})$. For the PV-only systems modeled in this analysis, ICAP Alternative 1 resulted in more revenue for the building load profiles and PV sizes modeled than ICAP Alternative 2. Residential and commercial load profiles in NYC experience high demand in the summer, and as a result, do not export enough over the identified 460 summer hours under ICAP Alternative 2 to take advantage of the higher export value. Buildings with lower consumption levels during summer afternoon hours (2 p.m. -6 p.m.) and larger PV sizes could potentially earn more revenue under Alternative 2, but that was not analyzed in this study because ICAP Alternative 1 was generally more lucrative for the solar developer.

\section{Adding storage to the PV system can allow the system to capture the demand reduction value (DRV)} or avoided demand ("D") and the locational system relief value (LSRV), though that is not guaranteed.

The DRV value is based on the amount that the system will reduce the distribution grid's peak demand. The LSRV is the additional value for locational-specific congestion relief in the distribution network. None of the scenarios modeled, including PV and storage, was able to capture any DRV or LSRV value. This was largely because building energy consumption is also typically very high when the grid's demand is peaking. Of the scenarios modeled during DRV/LSRV hours, on-site PV generation was only able to cover approximately $30 \%-50 \%$ of the building load and thus did not export. Storage systems would have to be significantly oversized to first satisfy the on-site load not met by PV generation and to then export any excess battery capacity to capture the benefits of DRV/LSRV during the appropriate hours. Oversizing storage incurs significant capital costs, which may not be fully offset by dispatching storage to capture the DRV/LSRV benefits. Additionally, DRV/LSRV compensation are determined retroactively, and so there is no guarantee these value streams will be captured by the storage system. Even with perfect foresight in the modeling simulations considered, battery systems failed to capture $30 \%-60 \%$ of the highest usage hours. The DRV/LSRV value streams are also hard to capture because the highest grid network loading hours are often consecutive, and the cost of a battery sized to discharge at high capacity for consecutive hours is greater than the DRV/LSRV benefits it would obtain.

\footnotetext{
${ }^{4}$ The ICAP summer window is 14:00 - 18:00 in June - August. Details can be found at the following location on the Con Edison website: https://www.coned.com/-/media/files/coned/documents/save-energy-money/using-privategeneration/specs-and-tariffs/value-stack-calculations.pdf?la=en

${ }^{5}$ The VDER ICAP options are summarized on the Con Edison Website at the following location: https://www.coned.com/-/media/files/coned/documents/save-energy-money/using-private-generation/specs-andtariffs/components-value-stack.pdf?la=en
} 


\section{Key Findings}

- Energy storage is the most cost-effective solution for mitigating interconnection requirements. Export mitigation with energy storage can improve project economics over the base case of only installing PV systems with no interconnection requirements.

- Results of the NREL analysis of VDER show that in the specific scenarios considered, VDER will lower revenue for system owners when compared with the current NEM compensation structure, but reductions are on the order of less than $1 \%$. If PV systems are installed only, ICAP Alternative 1 results in the highest revenue for the load profiles and PV sizes modeled. DRV/LSRV values are difficult to capture even with a perfect hourly load and PV generation forecast.

- Of the non-storage mitigation solutions evaluated here, curtailment and downsizing PV are found to be the next best options for export mitigation, depending on the rate tariff to which the customer is subscribed. Changing panel orientation across a wide range of angles to the sun is the least costeffective option available.

- The solutions show that encountering one or more of the Grid Ready criteria screens does not indicate a problematic site. With proper mitigation, including energy storage, a site can achieve favorable economics that match or surpass systems with PV only. 


\section{Table of Contents}

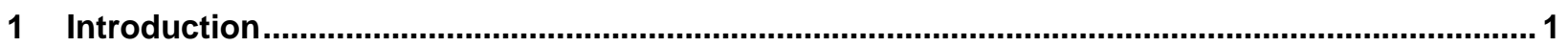

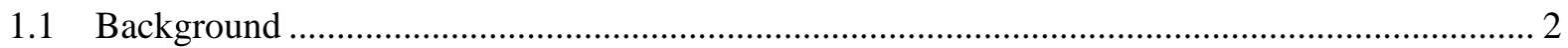

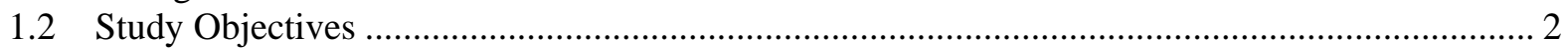

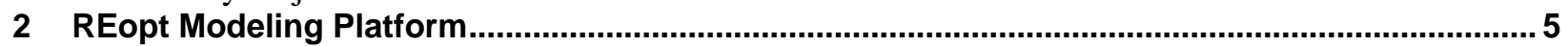

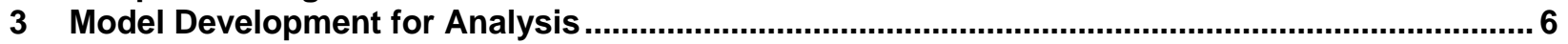

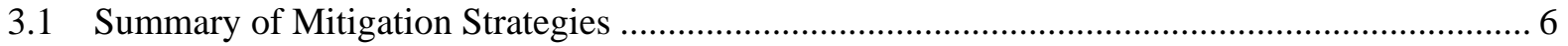

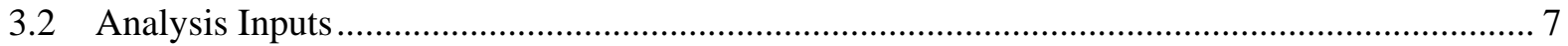

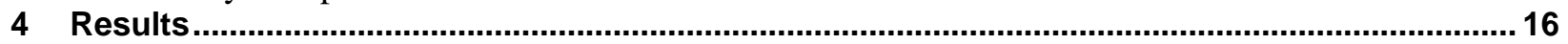

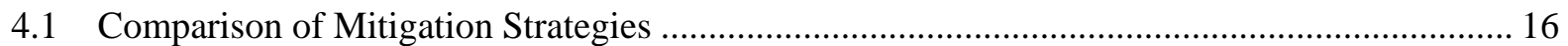

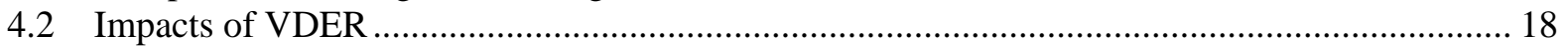

5 Pathway Forward and Future Work

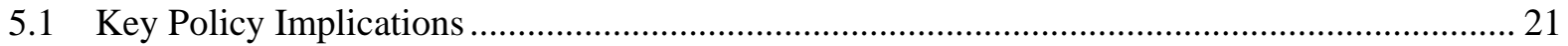

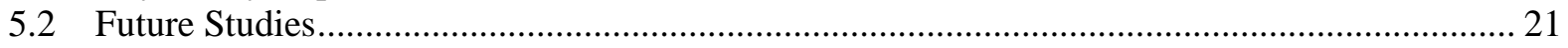

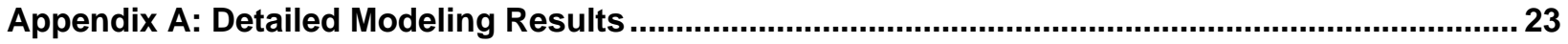

Appendix B: REopt Characteristics and Module Constraints ......................................................... 31

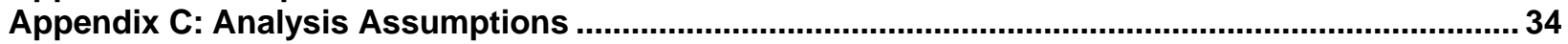




\section{Introduction}

The solar market in New York state has been growing steadily in recent years, and developers have been pursuing large-scale solar projects in New York City (NYC) as the demand for clean energy increases, prices drop, and the market becomes more mature. There are more than one million buildings in the five boroughs of New York City, and knowing the opportunity for large-scale ( $>200 \mathrm{~kW}$ ) solar potential at these building sites is valuable for the expansion of the market. Developing large-scale solar projects in such a dense urban environment requires a specific process and innovative integration solutions. Over the last few years, Consolidated Edison Company of New York, Inc. (Con Edison) has developed solutions such as upgrading network protector settings to facilitate exports to its secondary network grid. Phase 1 of the Grid Ready project took the next step in informing interconnection strategies: it was designed to (1) proactively inform developers of what interconnection requirements and costs may exist before they invest significant time and resources in developing the project and (2) provide optional strategies for navigating the interconnection process. This work is funded by the NY-SUN and is led by Sustainable CUNY in collaboration with Con Edison, ${ }^{6}$ the National Renewable Energy Laboratory (NREL), and New York State Energy Research and Development Authority (NYSERDA).

The interconnection of solar PV, especially on a large-scale on Con Edison's network and radial grid could cause adverse technical and reliability impacts in certain locations. Before launching the Grid Ready layer on the NY Solar Map in June 2017, developers-while they were able to call Con Edison for one-off interconnection feasibility checks or file a pre-application report-were unable to remotely screen where technical issues might arise, which could result in inaccurate project pricing or uncertainty about project timelines. In Phase I of the Grid Ready project, Sustainable CUNY, Con Edison, and NREL screened NYC buildings to determine those with large-scale PV potential and analyzed the technical factors associated with grid interconnection. The team also created a public resource to allow developers to look at individual sites, consider the impact of the interconnection requirements, and make informed decisions regarding project location and cost. More specifically, this resource is a layer on the CUNY-built NY Solar Map, showing whether buildings would likely require interconnection upgrades by screening sites for the three most common technical requirements associated with grid interconnection: (1) whether the building is on a spot/isolated network grid, (2) whether it has adequate service capacity, and (3) whether there is sufficient local load to absorb solar energy exported to the grid. Additionally, the public resource provides information regarding potential project interconnection requirements, a guide on the order of magnitude of costs for typical export mitigation strategies, and an overview of short-term and long-term solutions for buildings that face interconnection requirements.

In Phase 2 of the Grid Ready project, the focus of this report, Sustainable CUNY worked with NREL to evaluate a range of solutions for improving the economics of large-scale (over $200 \mathrm{~kW}$ ) PV within the five boroughs of New York City that are in Con Edison's service territory, as identified on the NY Solar Map. More specifically, NREL identified solutions for mitigating the export of large-scale solar energy from

\footnotetext{
${ }^{6}$ DISCLAIMER: Con Edison contributed to the creation of the Grid Ready tool in Phase 1 but was not involved in the analyses or conclusions in Phase 2. The analyses and conclusions in Phase 2 were developed solely by NREL and CUNY, and do not represent the views of Cons Edison.
} 
medium and low opportunity category buildings to the grid using multiple strategies, including adjusting the size or orientation of the solar PV, curtailing excess solar electricity production, or adding battery storage.

\subsection{Background}

The Con Edison electrical grid in New York state is one of the oldest and most complex electrical systems in the United States. In it, a mix of network grid, spot network, radial grid, above-ground infrastructure, and below-ground infrastructure were all constructed to safely and reliably deliver power to customers based on their expected loads. There are 46 distribution or area substations in NYC serving 57 networks with 1,070 primary feeders. A network may have 8-29 primary high-voltage-feeders connecting the area substation to the network. Approximately $86 \%$ of the electricity delivered by Con Edison is carried by an underground network distribution system. Depending on the desired location for a project, project size and operation, and grid characteristics, projects may be allowed to interconnect without upgrades or they may be required to pay for the cost of grid upgrades to accommodate export onto the electric grid without decreasing reliability or safety. It can be helpful for developers to understand these potential requirements and costs before moving down the development pipeline, as the requirements can greatly impact the value proposition of the project. In New York state, interconnection requirements are identified during the interconnection study. ${ }^{7}$

The Grid Ready project aims to reduce the costs of implementing large-scale projects and accelerate the rate at which projects are completed. For the first phase of the project, CUNY identified all buildings in NYC with enough rooftop space available to host a 200-kW or larger solar array using the data layer behind the NY Solar Map. Using the resulting list of 2,200 buildings Con Edison, analyzed each building to identify potential interconnection screens for each of the sites (referred to later in this document as the Grid Ready Data set) and provided information on typical technical solutions and available information on possible costs. This information was then posted to the NY Solar Map on a map layer that project developers can easily access. For the second phase of the project, NREL performed simulations for each of the mitigation strategies across different rate classes to determine which mitigation strategy was most cost effective. The outcome of this project is a resource that can be leveraged by the development community to determine which interconnection mitigation solutions could be considered for solar projects at specific sites and their associated potential costs. Using the resource, developers can decide whether a PV project is worth pursuing before investing significant time and effort into the site. Ultimately, the resource will result in a better understanding of site conditions, less industry time spent developing low opportunity sites, and more cost-effective projects for sites that have interconnection requirements.

\subsection{Study Objectives}

The goal of Phase 2 of the NYC Grid Ready Solar project is to assess and compare a set of PV export mitigation strategies for typical interconnection requirements in New York City.

A spot or isolated network is a utility installation designed with multiple high-voltage feeders and

\footnotetext{
${ }^{7}$ New York State Standardized Interconnection Requirements. www.dps.ny.gov/distgen.htm
} 
transformers tied to a common bus to ensure reliable electric service for large electric load users. The network protectors on these transformers are designed with an automatic safety feature by which the network protector opens when energy feeds back from the low-voltage bus toward the high-voltage feeder, which usually indicates a fault on the high-voltage cable. If a PV system were installed on a spot or isolated network and solar production were to exceed building load at any given time, the network protectors would detect the export of PV power as conditions analogous to those during a high-voltage feeder fault and open automatically, causing the electricity service to that building to go out. However, over the last few years, Con Edison has been able to offer a technical solution to allow export (and therefore net metering) of solar generation at these locations. This smart grid solution includes lowering the sensitivity of the network protectors to prevent them from opening under normal PV export conditions and installing supervisory control and data acquisition (SCADA) monitoring and communications equipment and anti-islanding relays in some cases.

Existing service cables feed into every building, and they are sized to provide enough capacity to serve the predicted peak electric load of the building. Inadequate service capacity refers to situations where the rating of conductors delivering power to each building is lower than the nameplate rating of the solar PV. Export is allowed up to the service cable ratings. If the service cable were not big enough to handle export equivalent to the rated PV system size, Con Edison would need to install additional service cables. Potential upgrades that would allow export to exceed the cable ratings are not considered in this report.

Inadequate local load refers to the limits of the load from local buildings in the surrounding area to absorb the excess PV generation exported from a building under consideration. The excess generation must be consumed by the buildings in the surrounding secondary network so that the network protectors feeding the area do not experience power backflow and open. PV installations can export, but export is limited to the lowest consumption measured in the surrounding area. Even if the building service can accommodate the PV export, a lightly loaded network may present technical complications for the area network grid if the local PV generation is greater than the local transformer loading. If the minimum load on the area network's transformers were too low to absorb the PV system's potential export at rated capacity, Con Edison would have to upgrade the settings at the local transformer network protectors. Since the publication of the Grid Ready map layer, Con Edison has published hosting capacity maps ${ }^{8}$ that will more accurately denote the "headroom" available for export to the grid.

To develop the Grid Ready Dataset, CUNY first identified all buildings in NYC with enough rooftop space available to host a 200-kW or larger solar array. Those not served by Con Edison distribution infrastructure and those with existing PV systems were not analyzed further. Of the 2,236 sites screened, 327 sites (14\%) were either not served by Con Edison distribution infrastructure or already had PV installations. Of the remaining sites, 928 (49\%) were on spot or isolated networks, while 980 (51\%) were not on spot networks. Of those not on spot networks, if a PV system covering the entire area available was installed, only 86 sites (4.5\%) would have no interconnection requirements. Figure 1 shows a breakdown of the Grid Ready Dataset sites by borough based on their interconnection requirements. Those facing interconnection requirements encountered the following screens:

8 “Hosting Capacity.” Con Edison, and Orange and Rockland. https://www.coned.com/en/business-partners/hostingcapacity. 
- Spot network grid: 928 sites (49\%)

- Inadequate service capacity: 381 sites (20\%)

- Inadequate local load: 819 sites (43\%)

\section{Grid Ready: Interconnection Requirements}

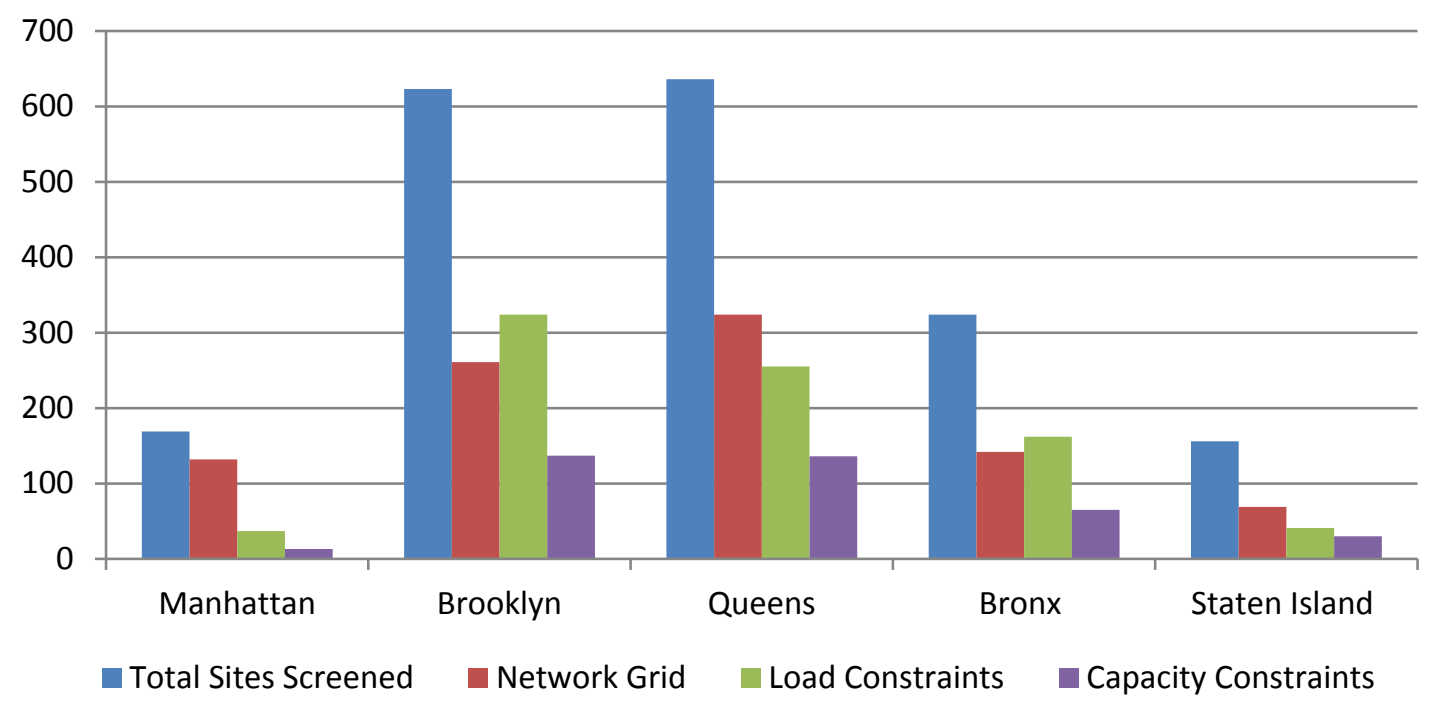

Figure 1: Sites in the Grid Ready Data set and interconnection requirements

For Phase 2, NREL compared the following set of mitigation strategies across a range of scenarios:

- Adjusting the size or orientation of the PV system

- Curtailing excess production

- Adding storage

- Implementing a combination of these strategies

The goal of this analysis was to identify the most cost-effective mitigation strategy under different export limitations and market structures so that developers can address interconnection requirements in the most cost-effective way possible. The appropriate export compensation scheme is also considered. Both the current net energy metering (NEM) framework and the new Value of Distributed Energy Resources (VDER) compensation structure were modeled in this analysis. 


\section{REopt Modeling Platform}

NREL's REopt model for energy systems integration and optimization was used to determine the most cost-effective export mitigation strategies. The model is based on a mixed-integer linear program that seeks to minimize the life cycle cost of energy at a site over the analysis period, subject to various constraints. The life cycle cost of energy considers:

- All costs associated with providing energy to the site, including the cost of purchasing energy from the utility grid

- Capital costs of building new technologies

- Operation and maintenance costs

- Income from utility or state incentive programs

- Any tax benefits

The REopt model performs an hourly simulation of the energy system, solving an energy balance (e.g., energy supply satisfies energy load) at every "time step" where loads must be met by some combination of renewable and conventional generation, purchased energy from the utility grid, discharges from energy storage, and dispatchable loads. This energy balance is solved for the first year and then assumed to repeat for each of the ensuing years in the analysis period. The model output is a set of cost-optimal sizes for each technology in the candidate pool and the net present value that is achieved if the technologies in the solution were implemented. The optimal dispatch strategy for each technology required to achieve the net present value is also provided.

A high-level overview of the REopt model, focusing on the components most relevant to the Grid Ready project, is provided in Appendix B. For additional details and mathematical formulations, refer to Cutler et al. (2017). ${ }^{9}$

\footnotetext{
${ }^{9}$ Cutler, Dylan, Dan Olis, Emma Elgqvist, Xiangkun Li, Nick Laws, Nick DiOrio, Andy Walker, and Kate Anderson (2017). "REopt: A Platform for Energy System Integration and Optimization,” NREL/TP-7A40-70022. National Renewable Energy Laboratory, Golden, CO 2017. https://www.nrel.gov/docs/fy17osti/70022.pdf
} 


\section{Model Development for Analysis}

This section summarizes the export mitigation strategies and modeling inputs considered within the Grid Ready project. Where relevant, data provided by Con Edison and other assumptions are listed.

\subsection{Summary of Mitigation Strategies}

For each interconnection screen within the Grid Ready criteria (i.e., spot network, inadequate service capacity, and inadequate local load), five mitigation strategies were analyzed and compared to a base case scenario. The base case scenario maximizes the amount of PV installed at each building type and calculates the total life cycle cost of the project if no export constraints are imposed in the model. In the base case scenario, PV panels are constrained to be south-facing and export is valued according to the modeled compensation schemes. For each scenario, total life cycle cost and energy and power exported are compared. For each of the Grid Ready criteria, three modeling scenarios are considered:

- Baseline: no constraints and no additional project costs

- Mitigation Strategies: export constraints and costs due to additional equipment

- Grid Solution: no constraints but additional costs due to system hardware upgrades.

The modeling scenarios broken out by Grid Ready criteria are shown in Table 1. Because service cable ratings were not known, capacity constraints were modeled by limiting export to be below building peak load as a proxy.

Table 1: Modeling Scenarios for Grid Ready Criteria

\begin{tabular}{|c|c|c|c|c|c|}
\hline \multicolumn{2}{|c|}{ Grid Ready Criteria } & \multirow{2}{*}{$\begin{array}{c}\text { Baseline } \\
\text { No Constraints }\end{array}$} & \multicolumn{2}{|c|}{ Mitigation Strategies } & \multirow{2}{*}{$\begin{array}{c}\begin{array}{c}\text { Grid } \\
\text { Solution }\end{array} \\
\text { No } \\
\text { Constraints }\end{array}$} \\
\hline \multirow{2}{*}{ 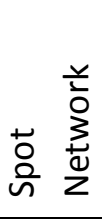 } & $\begin{array}{l}\text { Modeling } \\
\text { Constraints }\end{array}$ & & \multicolumn{2}{|c|}{ No Export } & \\
\hline & $\begin{array}{l}\text { Additional Costs to } \\
\text { Project }\end{array}$ & No Costs & Equipment & $\begin{array}{c}\text { Lower Energy } \\
\text { Production }\end{array}$ & Hardware \\
\hline \multirow{2}{*}{ 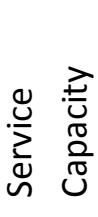 } & $\begin{array}{l}\text { Modeling } \\
\text { Constraints }\end{array}$ & No Constraints & \multicolumn{2}{|c|}{ Export Limited to Building Peak Load } & $\begin{array}{c}\text { No } \\
\text { Constraints }\end{array}$ \\
\hline & $\begin{array}{l}\text { Additional Costs to } \\
\text { Project }\end{array}$ & No Costs & Equipment & $\begin{array}{l}\text { Lower Energy } \\
\text { Production }\end{array}$ & Hardware \\
\hline \multirow{2}{*}{ 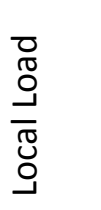 } & $\begin{array}{l}\text { Modeling } \\
\text { Constraints }\end{array}$ & No Constraints & \multicolumn{2}{|c|}{ No Export } & $\begin{array}{c}\text { No } \\
\text { Constraints }\end{array}$ \\
\hline & $\begin{array}{l}\text { Additional Costs to } \\
\text { Project }\end{array}$ & No Costs & Equipment & $\begin{array}{l}\text { Lower Energy } \\
\text { Production }\end{array}$ & Hardware \\
\hline
\end{tabular}

The five export mitigation strategies are:

1. PV sizing: System size is optimized to minimize life cycle energy cost while meeting export constraints. Panels are set to be south-facing and curtailment is not allowed.

2. PV orientation: PV size is set to the maximum that can fit on the specific building type and panel orientation is optimized to minimize life cycle energy cost while meeting export constraints. Nine 
possible orientations are considered, from $60^{\circ}$ to $300^{\circ}$, rotating by $30^{\circ}$ between each orientation option. Directly east-facing panels are at $90^{\circ}$, directly south-facing panels are at $180^{\circ}$, and directly west-facing panels are at $270^{\circ}$.

This is the only mitigation strategy that when used alone may result in failure of the Grid Ready test criteria, as generation at the most extreme orientation may still exceed export constraints. ${ }^{10}$ When no orientation solution meets the export criteria, the maximum PV size that can be installed without violating export constraints at the orientation with the least amount of export is found.

3. PV curtailment: Excess PV generation above the export constraint is curtailed. PV size is set to the maximum that can fit on the specific building type and panels are constrained to be south-facing.

4. Storage: Storage, in the form of Li-ion batteries, is optimally sized and dispatched, and it is paired with PV installations to meet export constraints. PV sizes are set to the maximum that can fit on each building type and panels are constrained to be south-facing. Curtailment is not allowed. The optimal storage size ( $\mathrm{kWh}$ ) and power delivery (kW) are determined independently. In the model, storage has perfect foresight, resulting in an upper bound for storage savings.

5. Combination: All the mitigation strategies above (PV sizing, orientation, curtailment, and storage) are considered and the mix of strategies that minimizes life cycle cost of energy is found.

Finally, the potential of load management to mitigate export is considered qualitatively. The hours during which the system typically exports in the unconstrained scenario are analyzed, and the types of loads that can be realistically shifted to these hours is discussed. The overall ability of load shifting to mitigate export is examined.

\subsection{Analysis Inputs}

How different Grid Ready inputs to the REopt model were obtained or derived is explained below. The way specific market structures are modeled, and other modeling considerations are also described.

\subsubsection{Rate Tariffs}

The four rate structures that are most common among buildings that can host large-scale solar in the Con Edison utility territory were considered in this analysis:

- SC-8 Rate I: multiple dwellings, $>10 \mathrm{~kW}$

- SC-8 Rate II: multiple dwellings, time-of-day charges

- SC-9 Rate I: general large buildings, $>10 \mathrm{~kW}$

- SC-9 Rate II: general large buildings, time-of-day charges

SC-8 rates are for master-metered residential distribution, while SC-9 rates are for commercial entities. Customers on the Rate I tariffs typically have an average demand of $50 \mathrm{~kW}$, while Rate II tariffs are for larger consumers with an average demand of $500 \mathrm{~kW}$. Each rate is composed of a fixed monthly fee (basic charge), a demand charge based on the peak 15-minute power usage each month, and a volumetric charge based on the number of kilowatt-hours used. Rate I tariffs vary by season (summer and winter),

\footnotetext{
${ }^{10}$ Orientation did not prevent export in all cases that were evaluated by REopt.
} 
while Rate II tariffs vary by both season and time of day. The charges associated with each rate structure are defined in Tables $\mathbf{2}$ through 6.

Table 2: Definitions of Periods Considered within Each Rate Structures Modeled

\begin{tabular}{|l|c|c|}
\hline & Summer (June-September) & Winter (October-May) \\
\hline High Peak & $8: 00-18: 00$ (Monday to Friday) & - \\
\hline On Peak & $8: 00-22: 00$ (Monday to Friday) & $8: 00-22: 00$ (Monday to Friday) \\
\hline All Times & All other periods & All other periods \\
\hline
\end{tabular}

Table 3: Rate Summary for SC-8 Rate I

\begin{tabular}{|l|c|c|}
\hline & Summer & Winter \\
\hline Basic Charge & $\$ 340.08$ & $\$ 262.90$ \\
\hline Demand Charge $(\$ / \mathrm{kW})$ & $\$ 43.95$ & $\$ 36.97$ \\
\hline Volumetric $(\$ / \mathrm{kWh})$ & $\$ 0.0983$ & $\$ 0.0983$ \\
\hline
\end{tabular}

Table 4: Rate Summary for SC-8 Rate II

\begin{tabular}{|l|c|c|c|c|c|}
\hline & \multicolumn{3}{|c|}{ Summer } & \multicolumn{2}{c|}{ Winter } \\
\hline Basic Charge & \multicolumn{3}{|c|}{$\$ 133.25$} & \multicolumn{2}{c|}{$\$ 133.25$} \\
\hline & High Peak & On Peak & All Times & On Peak & All Times \\
\hline Demand Charge $(\$ / \mathrm{kW})$ & $\$ 8.26$ & $\$ 17.25$ & $\$ 18.82$ & $\$ 11.91$ & $\$ 6.06$ \\
\hline Volumetric $(\$ / \mathrm{kWh})$ & & $\$ 0.080$ & $\$ 0.068$ & $\$ 0.080$ & $\$ 0.068$ \\
\hline
\end{tabular}

Table 5: Rate Summary for SC-9 Rate I

\begin{tabular}{|l|c|c|}
\hline & Summer & Winter \\
\hline Basic Charge & $\$ 159.02$ & $\$ 127.02$ \\
\hline Demand Charge $(\$ / \mathrm{kW})$ & $\$ 36.11$ & $\$ 31.23$ \\
\hline Volumetric $(\$ / \mathrm{kWh})$ & $\$ 0.085$ & $\$ 0.088$ \\
\hline
\end{tabular}

Table 6: Rate Summary for SC-9 Rate II

\begin{tabular}{|l|c|c|c|c|c|}
\hline & \multicolumn{3}{|c|}{ Summer } & \multicolumn{2}{c|}{ Winter } \\
\hline Basic Charge & \multicolumn{3}{|c|}{$\$ 133.25$} & \multicolumn{2}{c|}{$\$ 133.25$} \\
\hline & High Peak & On Peak & All Times & On Peak & All Times \\
\hline Demand Charge $(\$ / \mathrm{kW})$ & $\$ 24.22$ & $\$ 31.11$ & $\$ 32.22$ & $\$ 27.12$ & $\$ 21.14$ \\
\hline Volumetric $(\$ / \mathrm{kWh})$ & & & $\$ 0.071$ & & $\$ 0.074$ \\
\hline
\end{tabular}

An additional $8 \%$ sales tax and a $2.5 \%$ gross receipts tax are charged on all the rates above.

\subsubsection{Building Load}

Four representative building load profiles were simulated to correspond to each rate structure in Section 3.2.1, based on data from Con Edison. Con Edison provided hourly data for a typical summer, winter, and swing season day for an example of a building under each of the four tariffs. The shape of the load profile on the sample load days was then compared to the shape of the load profiles of the 16 building types in 
the U.S. Department of Energy Commercial Reference Buildings data set. ${ }^{11}$ The building type that most closely matched the data provided by Con Edison was selected to simulate one year of hourly load. The selected profiles were scaled to match the average annual consumption expected under each rate structure.

Figure 2 shows an example of the simulated load profiles over a summer week for buildings under the SC$8 \mathrm{I}$ and SC-9 I tariffs. Buildings under SC-8 rates have low demand overnight that increases to a small morning peak before steadily rising to a large evening peak; it is representative of typical residential consumption patterns. Commercial loads under SC-9 have a more constant demand throughout the day and a more distinctive reduction in load over the weekend. Simulated buildings under Rate II tariffs have identical consumption patterns, just scaled to a higher average demand.

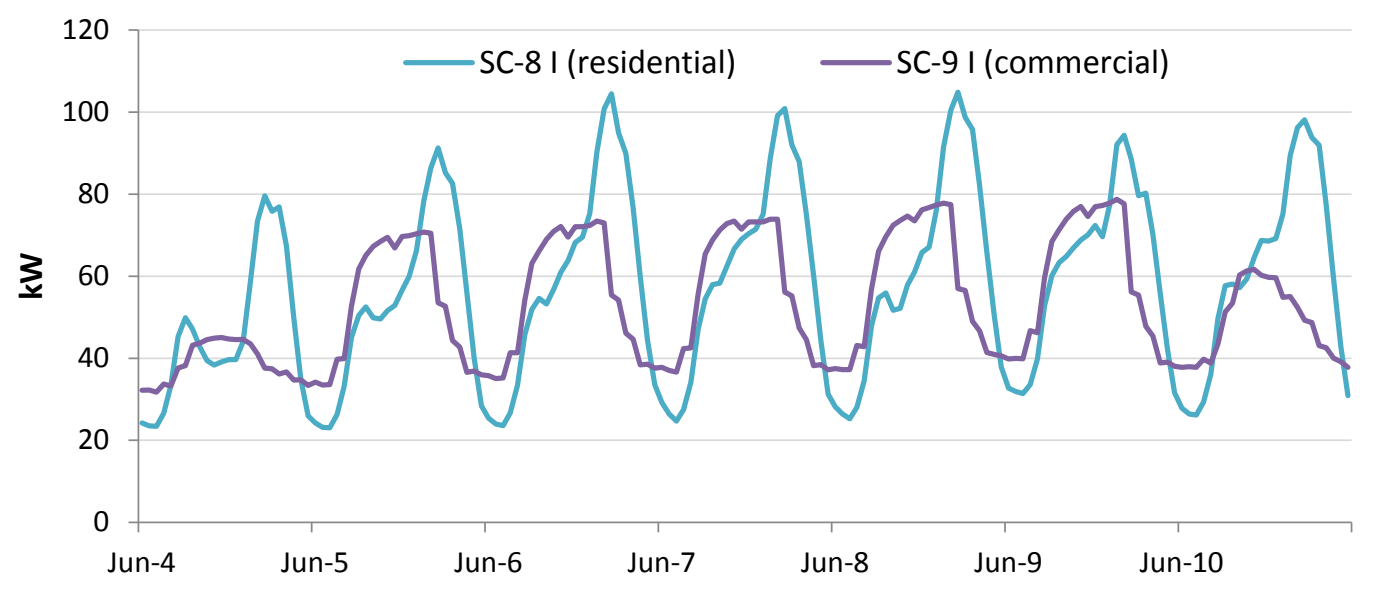

Figure 2: Simulated load profiles for SC-8 Rate I and SC-9 Rate I

\subsubsection{PV Sizing}

PV system sizes were scaled to building loads such that all base-case systems export and trigger failure of the Grid Ready test criteria. To avoid significantly oversizing the PV system for small buildings and undersizing for large buildings, the maximum PV size for each building was determined as a percentage of the peak building load.

The average PV system size in the Grid Ready Dataset is $467 \mathrm{~kW} .{ }^{12}$ According to Con Edison estimates, approximately $15 \%$ of buildings in this dataset are on the SC-8 I tariff, $15 \%$ are on the SC- 8 II tariff, 35\% are the SC-9 I tariff, and 35\% are on the SC-9 II tariff. Sizing the PV system under each of the four tariffs to $87 \%$ of peak building load results in a weighted average PV size of $467 \mathrm{~kW}$ across the scenarios, matching the average size of the Grid Ready Data set. The resulting maximum PV sizes considered for each building type are listed in Table 7.

\footnotetext{
${ }^{11}$ Office of Energy Efficiency and Renewable Energy (2017). “Commercial Reference Buildings.” https://energy.gov/eere/buildings/commercial-reference-buildings.

${ }^{12}$ The Grid Ready Dataset is made up of all buildings in New York City able to accommodate PV systems $200 \mathrm{~kW}$ and larger on their rooftops.
} 
Table 7: PV Sizing at Buildings under Each Rate Structure

\begin{tabular}{|l|c|}
\hline & PV size (kW) \\
\hline Rate Tariff & 115 \\
\hline SC-8 I & 1,150 \\
\hline SC-9 I & 72 \\
\hline SC-9 II & 720 \\
\hline
\end{tabular}

\subsubsection{Costs and Economic Assumptions}

Given the study's goal of identifying the most cost-effective export mitigation strategies, the maximum PV size that can fit on each building must be economical or the optimization will always choose to reduce system size for economic reasons alone and not purely as a mitigation strategy in response to export constraint violations. To fairly compare all mitigation strategies, installed PV costs were adjusted to be at the break-even point at which the desired system size just becomes cost-effective. They are the highest possible PV costs at which the maximum PV size is still economical to build. These costs, shown in Appendix $\mathrm{C}$, do not account for available incentives.

Battery costs and other economic assumptions are listed in Table 8. It is assumed batteries can only be charged from PV (and not the utility grid) in order to claim the full federal investment tax credit. The cost of one battery replacement is included at projected future costs. 
Table 8: Economic Assumptions and Battery Costs

\begin{tabular}{|l|l|}
\hline Analysis Period & 25 years \\
\hline Ownership Model & Third-party financed (power purchase agreement) \\
\hline Off-taker discount rate & $3 \%$ \\
\hline Developer discount rate & $10 \%$ \\
\hline General inflation $^{13}$ & $-0.6 \%$ \\
\hline Electricity escalation rate $^{6}$ & $1.52 \%$ \\
\hline Incentives & $30 \%$ investment tax credit (PV and battery) \\
\cline { 2 - 2 } & $\begin{array}{l}\text { Five-year MACRS (Modified Accelerated Cost Recovery System) } \\
\text { (PV and battery) }\end{array}$ \\
\cline { 2 - 2 } & $\$ 0.50 / \mathrm{W}$ MW-Block Grant (PV) \\
\hline Battery cost ${ }^{14,15}$ & $\$ 500 / \mathrm{kWh}+\$ 1,000 / \mathrm{kW}$ \\
\hline Battery replacement cost ${ }^{16}$ & $\$ 230 / \mathrm{kWh}+\$ 460 / \mathrm{kW}$ \\
\hline Battery replacement year & One replacement occurs over the project life cycle (in Year 10). \\
\hline
\end{tabular}

Finally, the interconnection costs needed to implement the new projects and mitigation strategies are also considered. Most costs are specific not to a mitigation strategy but to whether the PV installation will occur on a spot/isolated network, secondary network, or a radial grid. Table $\mathbf{9}$ outlines the additional power system costs for various scenarios. As per the New York State Standardized Interconnection Requirements, network interconnections will most likely incur a Coordinated Electric System Interconnection Review (CESIR) study cost, and depending on whether grid upgrades are required, other costs are added.

\footnotetext{
${ }^{13}$ Lavappa, Priya D., Joshua D. Kneifel, and Eric G. O’Rear (2017). "Energy Price Indices and Discount Factors for Life-Cycle Cost Analysis: 2017 Annual Supplement to NIST Handbook 135.” http://nvlpubs.nist.gov/nistpubs/ir/2017/NIST.IR.85-3273-32.pdf.

${ }^{14}$ GTM Research, and the Energy Storage Association (2017). "U.S. Energy Storage Monitor: Q2 2017 Full Report.” GTM Research. https://www.greentechmedia.com/research/subscription/u-s-energy-storage-monitor. ${ }^{15}$ Ortiz, Luis, and Ravi Manghani (2016). "Grid-Scale Energy Storage Balance of Systems 2015-2020: Architectures, Costs and Players.” GTM Research. https://www.greentechmedia.com/research/report/grid-scaleenergy-storage-balance-of-systems-2015-2020.

${ }^{16}$ Schmidt, O., A. Hawkes, A. Gambhir, and I. Staffell (2017). "The Future of Electrical Energy Storage based on Experience Rates.” Nature Energy. https://energy.gov/eere/buildings/commercial-reference-buildings
} 
Table 9: Interconnection and Grid Hardware Costs for Future PV interconnections

\begin{tabular}{|l|c|c|}
\hline All Projects/Scenarios & \multicolumn{1}{|c|}{ Cost } & Project type \\
\hline CESIR study & $\$ 20,000^{17}$ & All \\
\hline Systems without Export & $\$ 10,000$ & All \\
\hline Reverse power relay & $\$ 75,000$ & Spot or isolated \\
\hline Systems with Export & $\$ 15,000$ & Radial \\
\hline Communication-aided tripping technology & & \multicolumn{2}{|c|}{ All } \\
\hline Advanced network protector relay settings & $\$ 25,000$ & $\begin{array}{c}\text { (if curtailment is } \\
\text { enabled) }\end{array}$ \\
\hline $\begin{array}{l}\text { System Production Can Be Curtailed } \\
\text { Curtailment technology (includes local controller, ethernet switch, } \\
\text { media converters, fiber optic cable, new current transformers, and } \\
\text { new meters to allow communication between the export meter and } \\
\text { inverter) }\end{array}$ & & \begin{tabular}{l}
$\mid$ \\
\hline
\end{tabular}
\end{tabular}

Because they do not impact which mitigation strategy is chosen, interconnection costs are added postoptimization. However, curtailment technology costs are modeled, so that REopt can chose either to not curtail or to curtail and incur a $\$ 25,000$ cost penalty.

\subsubsection{Export Compensation Schemes}

Two export compensation schemes are modeled within the Grid Ready analysis: the current NEM framework based on historical data from 2016 and the new VDER mechanism with anticipated rates that New York state is transitioning toward.

\subsubsection{Net Energy Metering}

Average 2016 net metering compensation by service class was used to estimate the value of energy exports under NEM. A constant value was assumed for all energy exported during the analysis period. Table 10 shows the rates used in this analysis.

Table 10: Value of Exported energy for Each Service Class

\begin{tabular}{|l|l|}
\hline Rate & Export Value \\
\hline SC-8 & $\$ 0.102 / \mathrm{kWh}$ \\
\hline SC-9 & $\$ 0.107 / \mathrm{kWh}$ \\
\hline
\end{tabular}

\subsubsection{Value of Distributed Energy Resources}

New York state is currently transitioning from NEM to VDER, a values-based spatiotemporal compensation scheme that seeks to compensate solar project developers for the distributed energy generation they export to the grid. Under VDER, export payments change based on when and where the export occurs. Unlike NEM, which only credits the net energy exported at the end of a billing cycle, VDER payments are applied to all export. The Grid Ready analysis quantifies the impacts on export mitigation strategies and system economics as NYC moves from NEM to VDER.

\footnotetext{
${ }^{17}$ Based on current estimates of maximum interconnection study for inverter-based projects
} 
Under Phase I of VDER, the value of export is comprised of the six components described below and shown in Figure 3:

1. Energy: Compensation is determined based on day-ahead hourly locational-based marginal prices (LBMP).

2. Generating Capacity: Three options are available to credit the energy exported: ICAP Alternatives 1,2 , and 3. By default, intermittent generation starts with Alternative 1 compensation but may choose to switch to Alternatives 2 or 3. Dispatchable resources, including PV paired with storage, are only eligible under Alternative 3 .

ICAP Alternative 1 values all export throughout the year, providing a dollar per kilowatt-hour $\$ / k W h$ capacity payment for all energy fed back to the grid. Alternative 1 changes every six months, with separate winter (November-April) and summer (May-October) rates. ICAP Alternative 2 only credits exports during on-peak summer periods, which are defined as the 460 hours from June to August between 2 p.m. and 6 p.m. A $\$ / \mathrm{kWh}$ value is paid only toward export in the defined summer period; this value is updated annually. Capacity payments on Alternative 2 are higher than those on Alternative 1.

Compensation under ICAP Alternative 3 is determined by applying the monthly ICAP spot auction value to a customer's annual ICAP export tag. This export tag is defined as the kilowatts of export during the peak load hour in New York state in the previous capability year. If the system did not export during the hour the grid peaked, the customer does not receive any ICAP compensation.

3. Renewable Energy Credit: VDER provides an environmental credit for customers who forgo their renewable energy certificates and instead choose to get compensation through the value stack. The utility then gets the customer's renewable energy certificate, and the customer is paid the higher of two values:

- The social cost of carbon per kilowatt-hour minus the value of the Regional Greenhouse Gas Initiative or

- The applicable NYSERDA Tier 1 renewable energy certificate price per kilowatt-hour.

The environmental value is constant for all energy exported throughout the year. It is locked in at interconnection and fixed for the VDER compensation term.

4. Demand Reduction Value/Avoided Demand (DRV or "D"): This value stream provides additional compensation for export during the 10 peak distribution hours of the previous year. These top 10 load hours are identified separately for each Commercial System Relief Program (CSRP) zone. CSRP zones group electrical networks within the Con Edison territory that tend to peak at similar times. Credits for DRV are determined based on a project's ability to offset peak electricity use in the CSRP zone where the project is located. For the best coincidence with PV generation, it is assumed that buildings in this analysis are in the CSRP zone, which typically peaks between 11 a.m. and 3 p.m.

To identify the 10 peak load hours in this analysis, ambient temperature was used as a proxy. A typical meteorological year temperature profile for New York City was sorted, and the top 10 
hottest weekday hours between July and September were found. These were validated against data of the highest load hours in the 11 a.m.-3 p.m. CSRP zone from 2012 to 2015.

The weighted average of the power exported during these 10 highest load hours is multiplied by the applicable DRV rate, divided by 12 , and paid on a monthly basis beginning January of the following year. The DRV value is based on the utility's avoided marginal cost of service, and only customers not receiving the Market Transition Credit (MTC) are eligible (the DRV is effectively built into the MTC for customers receiving that credit).

5. Locational System Relief Value (LSRV): LSRV payments provide an additional incentive for distributed generation developed in high-value areas. They are added to DRV compensation for resources located in eligible regions, and so are calculated in the same manner as DRV payments. High-value areas are determined based on the loading levels of the subtransmission and distribution networks. Approximately $19 \%$ of Con Edison territory is considered "high-value."

6. Market Transition Credit (MTC): The MTC is only available for community distributed generation projects. This credit bridges the transition between NEM and VDER for mass-market customers based on tranches of system capacity. This value stream is not applicable to buildings considered in the Grid Ready project.

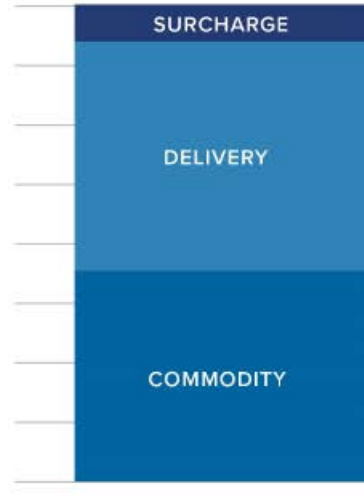

Base Retail Rate (NEM)

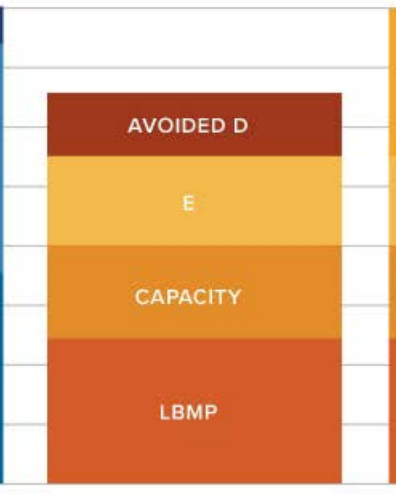

Value Stack (Onsite or RNM)

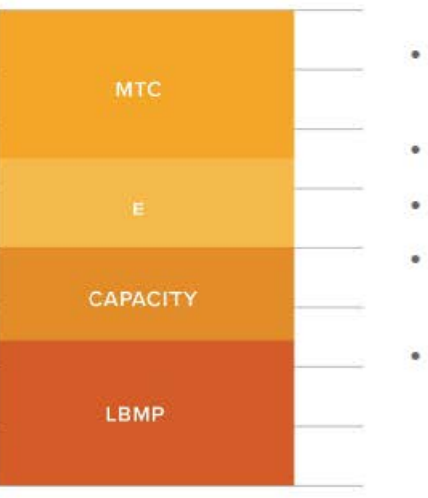

Value Stack + MTC (CDG)
- Avoided D - avoided demand

- E - environmental benefit

- Capacity - ICAP

- LBMP - energy commodity

- MTC - market transition credit for CDG

Figure 3: VDER Phase One value stack components ${ }^{18}$

The values assumed for each component of the Value Stack are summarized in Table 11. All estimates are provided by Con Edison through a Value of DER Developer Workshop ${ }^{19}$ and are subject to commission approval.

\footnotetext{
${ }^{18}$ VDER and Phase 1 Implementation Order Overview (10/13/2017). NYSERDA. "Summary of Value of Distributed Energy Resources,” https://www.nyserda.ny.gov/-/media/VDER-P1-Implementation-OrderOverview.pdf.

${ }^{19}$ Con Edison, and Orange and Rockland (2017). "Value of DER: Developer Workshop.” https://www.coned.com//media/files/coned/documents/save-energy-money/using-private-generation/specs-and-tariffs/vder-
} 
Table 11: Estimated Values for Each Component of the VDER Value Stack

\begin{tabular}{|c|c|c|}
\hline \multicolumn{2}{|c|}{ Value Stack Component } & Assumed Value \\
\hline \multicolumn{2}{|l|}{ Energy } & Hourly 2016 LBMP values ${ }^{20}$ \\
\hline \multirow[b]{3}{*}{$\begin{array}{l}\text { Generating } \\
\text { Capacity }\end{array}$} & ICAP Alternative 1 & $\begin{array}{l}\$ 0.03584 / \mathrm{kWh} \text { (all summer hours, May-October) } \\
\$ 0.00905 / \mathrm{kWh} \text { (all winter hours, November-April) }\end{array}$ \\
\hline & ICAP Alternative 2 & $\$ 0.33883 / \mathrm{kWh}$ (460 summer hours) \\
\hline & ICAP Alternative 3 & $\begin{array}{l}\text { Export tag: August } 11,4 \text { p.m. (peak network loading hour } \\
\text { from } 2016 \text { data) }{ }^{21} \\
\text { Monthly ICAP auction values: one year of historical monthly } \\
\text { spot prices from NYISO's ICAP market }{ }^{22} \\
\text { Price range: } \$ 2.61 / \mathrm{kW}-\$ 10.11 / \mathrm{kW}\end{array}$ \\
\hline \multicolumn{2}{|c|}{ Renewable Energy Credit } & $\$ 0.02424 / \mathrm{kWh}$ \\
\hline \multicolumn{2}{|l|}{ DRV } & $\$ 199.40 / k W$-year \\
\hline \multicolumn{2}{|l|}{ LSRV } & $\$ 140.76 / k W-y e a r$ \\
\hline \multicolumn{2}{|l|}{ MTC } & Not applicable \\
\hline
\end{tabular}

workshop.pdf?la=en

${ }^{20}$ NYISO Historical Day Ahead Average Hourly Zonal Pricing

${ }^{21}$ Yeomans, Wes (2016). "NYISO Summer 2016 Hot Weather Operations.”

http://www.nyiso.com/public/webdocs/markets_operations/committees/mc/meeting_materials/2016-0928/Summer\%202016\%20NYISO\%20Hot\%20Weather\%200perating\%20Conditions.pdf.

${ }^{22}$ NYISO (2017). “Spot Auction Summary.” http://icap.nyiso.com/ucap/public/auc_view_spot detail.do 


\section{Results}

\subsection{Comparison of Mitigation Strategies}

Mitigation strategies are expected to increase project life cycle costs when compared to the base case scenario of installing stand-alone PV systems with no interconnection limits, because they are implemented to address new export requirements and they include additional technology and grid hardware costs. However, the economics of storage in New York state is sufficiently favorable that adding storage lowered total life cycle cost in almost all the scenarios considered. Storage, in combination with some curtailment or export, is the most cost-effective export mitigation strategy across all the modeled building types, rate structures, export constraints, and export compensation schemes. Table 12 shows the most cost-effective mitigation strategy for each scenario modeled, and Table 13 shows the reduction in total life cycle cost that the most cost-effective mitigation strategy was able to achieve when compared to the unconstrained base case. Export in the base case is compensated through either NEM or VDER as specified by the scenario.

Table 12: The Most Cost-Effective Export Mitigation Strategies Chosen for Each Scenario Modeled

\begin{tabular}{|c|c|c|c|c|c|}
\hline & & SC-8I & SC-8 II & SC-9 I & SC-9 II \\
\hline \multirow{3}{*}{ NEM } & No export & stor & ment & $\begin{array}{c}\text { storage }+ \\
\text { reduced PV sizing }\end{array}$ & storage only \\
\hline & Spot/isolated network & \multirow{2}{*}{\multicolumn{4}{|c|}{ storage + export }} \\
\hline & Radial grid & & & & \\
\hline \multirow{3}{*}{ VDER } & No export & stor & ment & $\begin{array}{c}\text { storage + } \\
\text { reduced PV sizing }\end{array}$ & storage only \\
\hline & Spot/isolated network & \multirow{2}{*}{\multicolumn{4}{|c|}{ storage + export }} \\
\hline & Radial grid & & & & \\
\hline
\end{tabular}

Table 13: Reduction in Total Life Cycle Cost Achieved by the Most Cost-Effective Mitigation Strategy

\begin{tabular}{|c|c|c|c|c|c|}
\hline & & SC-8 I & SC-8 II & SC-9 I & SC-9 II \\
\hline \multirow{3}{*}{ NEM } & No export & $6.70 \%$ & $13.24 \%$ & $2.43 \%$ & $11.31 \%$ \\
\hline & Spot/isolated network & $4.86 \%$ & $13.40 \%$ & $-1.59 \%$ & $11.10 \%$ \\
\hline & Radial grid & $8.06 \%$ & $13.67 \%$ & $2.28 \%$ & $11.32 \%$ \\
\hline \multicolumn{2}{|r|}{ Average } & $6.54 \%$ & $13.44 \%$ & $1.04 \%$ & $11.25 \%$ \\
\hline \multirow{3}{*}{ VDER } & No export & $7.50 \%$ & $13.85 \%$ & $2.46 \%$ & $11.33 \%$ \\
\hline & Spot/isolated network & $5.48 \%$ & $13.69 \%$ & $-1.57 \%$ & $11.09 \%$ \\
\hline & Radial grid & $8.66 \%$ & $13.95 \%$ & $2.30 \%$ & $11.31 \%$ \\
\hline \multicolumn{2}{|r|}{ Average } & $7.21 \%$ & $13.83 \%$ & $1.06 \%$ & $11.24 \%$ \\
\hline
\end{tabular}


As can be seen in Table 13, the mitigation strategy reduced total life cycle costs in almost all cases. The exception is a commercial building on the SC-9 I tariff and located on a spot/isolated network. In these cases, the utility bill savings afforded by the storage systems from demand charge reduction and energy arbitrage opportunities were less than the interconnection costs needed to retain reliable electric service and to allow for export on a spot/isolated network.

To meet network grid requirements in the scenario when the system export is limited, storage with some curtailment was the most cost-effective mitigation strategy for residential profiles on the SC-8 tariffs. Downsizing storage provided enough savings to overcome the additional grid hardware costs needed to implement curtailment. However, for commercial profiles on the SC-9 tariffs, storage only or storage with a small reduction in PV size was most cost-effective. The optimized solution chose not to incur the additional cost of enabling curtailment.

Because the service cable ratings were not known in the model, capacity constraints were modeled by limiting export to be below building peak load as a proxy. However, in the scenarios considered, building peak load was greater than the maximum PV capacity at each building, so export became effectively unconstrained for the capacity-constrained scenarios. No mitigation strategy was required to meet technical limits, but in all cases modeled, installing some storage reduced total life cycle costs. Reduced storage sizes (as compared to the no export scenarios) with limited export became the most cost-effective mitigation strategy. Storage sizes in kilowatt-hours reduced by an average of $12 \%$, while inverter sizes reduced by approximately $6 \%$ when compared to the no export scenarios.

Curtailment was the second most cost-effective mitigation strategy for residential units subscribing to SC8 tariffs and not exporting, increasing life cycle costs by an average of $3.5 \%$ as compared to the unconstrained base case. For commercial systems under SC-9 rates, reduced PV sizing was the second most cost-effective export mitigation strategy for avoiding all export. PV system sizes decreased by approximately $28 \%$, which corresponds to an increase in life cycle energy costs of about $0.5 \%$. Including grid hardware, there was an increase of $0.10 \%-4.80 \%$ in life cycle costs for new PV installations on spot/isolated networks and an increase of $0.05 \%-0.98 \%$ in life cycle costs for installations on the radial grid.

Load constraints were not modeled directly in this analysis because there is an effective way to estimate the amount of load that surrounding buildings can absorb for a set of hypothetical buildings. However, the network grid and capacity constraints modeled represent the lower and upper bounds on export, with load constraints likely to fall in between. Therefore, this analysis shows the upper and lower ranges of potential solutions. Detailed numerical results for each scenario, outlining total life cycle costs, amount of PV energy and power exported or curtailed, and specific system sizes and configurations, are found in Appendix A.

While it was not modeled explicitly, load shifting is another export mitigation strategy system owners can utilize. An example of a load profile is shown in Figure 4. In this scenario, when PV size is maximized, export occurs between 9 a.m. to 2 p.m. sporadically throughout the year. Site consumption can be shifted to these hours during high PV generation or low load days to minimize export. Examples of loads that can be shifted include: 
- HVAC loads (e.g., indoor space heating and cooling requirements)

- Loads with thermal inertia (e.g., refrigeration and domestic water heating)

- Large household appliances (e.g., washers, dryers, and dishwashers on a timer)

- Building lighting systems (e.g. dimming certain non-critical circuits)

- Pool pumps in apartment complexes

- Electric vehicle charging

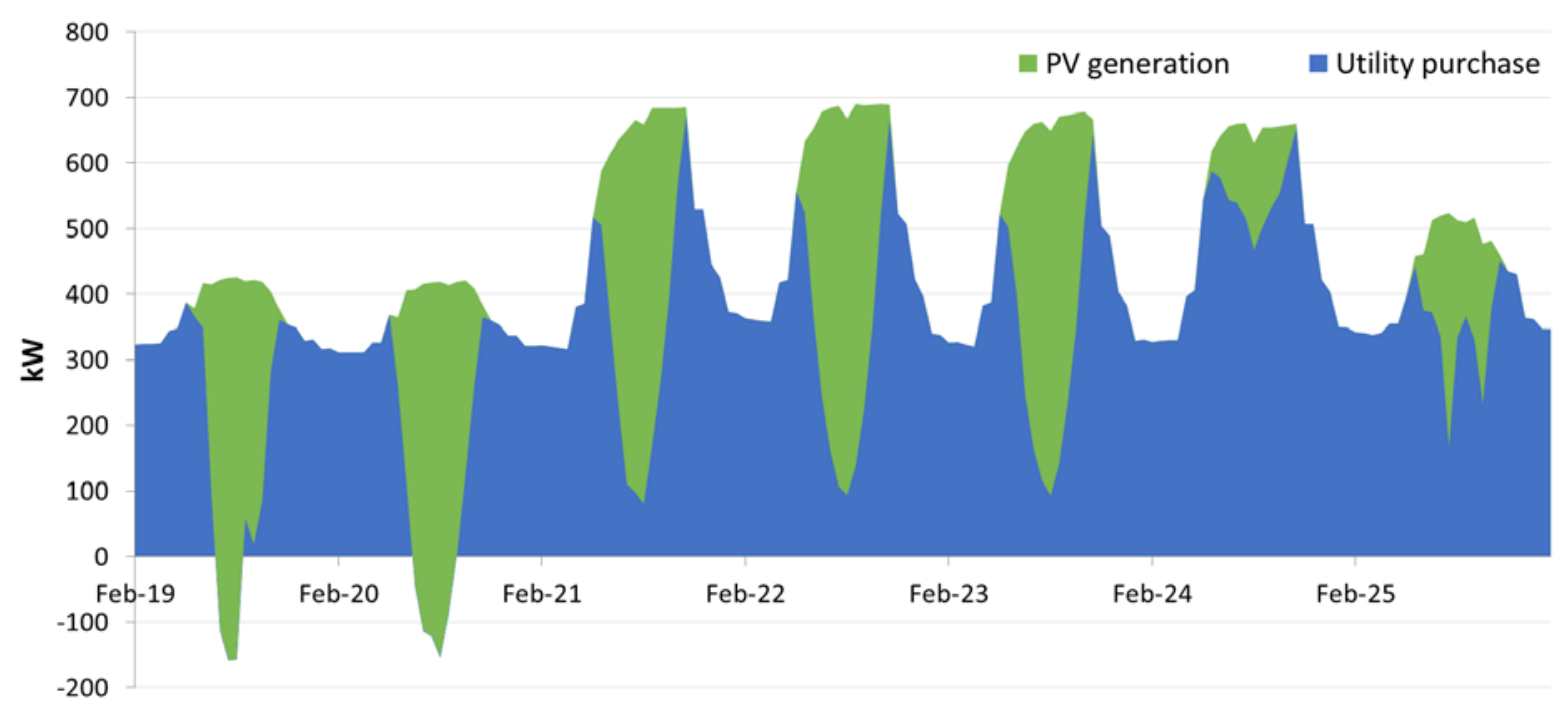

Figure 4: Example of base case load and PV generation for a building on SC-9 II

Building load shifting is often one of the lowest-cost options for mitigating energy export. Many of the tools that are needed to implement a load shifting program are already in place or come as standard features on devices. More devices with load scheduling capabilities are expected to come to market in the coming years.

\subsection{Impacts of VDER}

In all the scenarios considered, PV system owners on both large residential and commercial buildings obtained less revenue under VDER than under the current NEM compensation scheme. However, the differences are small. Table 14 shows the change in base case stand-alone PV life cycle cost for each of the buildings and rate structures analyzed. Base case scenarios maximize the PV installed at each building and do not impose export constraints.

Table 14: Change in Stand-Alone PV Project Life Cycle Cost Moving from NEM to VDER

\begin{tabular}{|c|c|c|c|c|}
\hline $\begin{array}{c}\text { Rate } \\
\text { Structure }\end{array}$ & $\begin{array}{c}\text { Base Case Life Cycle } \\
\text { Cost under NEM }\end{array}$ & $\begin{array}{c}\text { Base Case Life Cycle } \\
\text { Cost under VDER }\end{array}$ & $\begin{array}{c}\text { Cost Difference } \\
\text { between VDER and } \\
\text { NEM }\end{array}$ & $\begin{array}{c}\text { Increase in Life Cycle } \\
\text { Cost Moving from NEM } \\
\text { to VDER }\end{array}$ \\
\hline SC-8 I & $\$ 1,873,200$ & $\$ 1,889,570$ & $\$ 16,370$ & $0.874 \%$ \\
\hline SC-8 II & $\$ 22,998,900$ & $\$ 23,162,500$ & $\$ 163,600$ & $0.711 \%$ \\
\hline SC-9 I & $\$ 1,552,150$ & $\$ 1,552,630$ & $\$ 480$ & $0.031 \%$ \\
\hline SC-9 II & $\$ 27,903,600$ & $\$ 27,908,300$ & $\$ 4,700$ & $0.017 \%$ \\
\hline
\end{tabular}


Additional results are considered separately for export mitigation scenarios with PV systems only and scenarios with PV and storage, as they are compensated differently under VDER.

\subsubsection{Scenarios with only PV installations}

Once the setup of the installation is decided, the main compensation decision for intermittent systems under VDER is whether to subscribe to ICAP Alternative 1 or 2. For the load profiles and system sizes modeled in this analysis, more revenue was obtained on ICAP Alternative 1. Both the representative residential and commercial load profiles experience high demand in the summer in the NYC climate zone, and do not export enough over the identified 460 summer hours under ICAP Alternative 2 to take advantage of the higher export value. Therefore, in all the presented results, it is assumed buildings with PV systems only subscribe to Alternative 1 . It is possible that buildings with (A) lower consumption levels during summer afternoon hours between 2 p.m. and 6 p.m. or (B) larger PV sizes would earn more revenue on Alternative 2 , but that was not analyzed in this study.

Furthermore, none of the scenarios modeled was able to capture any DRV or LSRV compensation. PV systems interconnected to the distribution network are compensated for export during the 10 peak load hours on the network. However, self-consumption is typically also high when the network is peaking. Of the scenarios modeled, PV generation during the DRV/LSRV hours only covered approximately $30 \%-50 \%$ of the site load and thus did not export.

\subsubsection{Scenarios with $P V$ and storage}

Once storage is incorporated as a mitigation strategy, the installed system is classified as dispatchable and must switch to ICAP Alternative 3, under which compensation depends on an annual export tag based on how much the system was exporting during the peak load hour of the previous year in New York state. Furthermore, adding storage can allow the system to take advantage of the DRV/LSRV value streams. However, the hours for the ICAP export tag and DRV/LSRV compensation are determined retroactively, so there is no guarantee they can be captured by the storage system.

Because REopt performs a deterministic optimization-to model this uncertainty and to quantify how large the DRV/LSRV values streams are-three cases were compared:

1. Case 1: Systems were optimized without considering ICAP or DRV/LSRV compensation. Any revenue derived from these value streams that was due to export that happened to coincide with the peak hours were calculated and added post-optimization.

2. Case 2: The optimization model is told exactly when the hour for the ICAP export tag and the 10 hours for DRV/LSRV value occur. The battery is optimally sized and dispatched with the option of capturing these value streams. This is the upper bound on performance, as the optimization has perfect foresight when in reality these hours are not known in advance.

3. Case 3: A non-optimal dispatch schedule was tested, forcing the battery to dispatch during hot summer afternoons in hopes of capturing the ICAP export tag and DRV/LSRV value hours.

Comparing the results of optimizing with and without the ICAP and DRV/LSRV value streams (Case 1 and Case 2 above), storage sizes were significantly increased, but cost savings were minimal (Table 15). 
Table 15: Changes in Storage Sizes and Life Cycle Cost when DRV/LSRV Value Hours are Known

\begin{tabular}{|l|c|c|c|}
\hline & $\begin{array}{c}\text { Percentage } \\
\text { Increase in } \\
\text { Storage (kWh) }\end{array}$ & $\begin{array}{c}\text { Percentage } \\
\text { Increase in } \\
\text { Storage (kW) }\end{array}$ & $\begin{array}{c}\text { Percent Life } \\
\text { Cycle Cost } \\
\text { Saved (LCC) }\end{array}$ \\
\hline SC-8 I & 27.8 & 162.2 & 4.9 \\
\hline SC-8 II & 30.1 & 112.3 & 4.1 \\
\hline SC-9 I & 0.0 & 0.0 & 0 \\
\hline SC-9 II & 32.7 & 192.6 & 1.0 \\
\hline
\end{tabular}

Storage systems must be significantly oversized to first meet the site load not covered by PV generation and then to export any excess battery capacity during the identified hours. Oversizing storage incurs significant capital costs, which may not be fully recouped if the system is unable to predict exactly when to dispatch. However, even with perfect foresight of when the DRV/LSRV value hours occur, the system still fails to capture approximately 3 to 6 of the top 10 DRV/LSRV load hours in the scenarios considered. DRV/LSRV values are hard to capture as the highest network loading hours are often consecutive, and the cost of a battery sized to discharge at high capacity for consecutive hours is greater than the DRV/LSRV value it obtains. This makes it difficult to achieve significant savings.

Because cost savings are minimal, especially in the case of commercial buildings under SC-9 rates because of the alignment of their consumption patterns with PV generation and network peaking hours, any nonoptimal dispatch strategy tested (Case 3 above) resulted in worse life cycle economics than optimizing while ignoring the ICAP and DRV/LSRV value streams. 


\section{Pathway Forward and Future Work}

\subsection{Key Policy Implications}

While this analysis focused on mitigating interconnection requirements for large-scale solar PV systems on buildings in NYC, the results can help inform solar projects of all sizes and influence project development work in NYC going forward. Despite the pending transition to a VDER compensation policy in NYC, a solar project developer targeting large residential (SC-8) and commercial (SC-9) buildings in NYC will be able to make revenues installing solar PV systems on these types of buildings that are similar to those they made under NEM. This provides greater market certainty for the future regarding the financial feasibility of developing large-scale solar projects in NYC for on-site building consumption and export to the grid. Additionally, when facing solar PV grid interconnection requirements as described above, adding battery storage not only helps mitigate these requirements but can actually improve the project's economics over the base case of only installing PV systems. While grid interconnection mitigation strategies are generally expected to increase project life cycle costs, storage consistently lowered total life cycle costs and was the most cost-effective mitigation strategy across the board. Finally, capturing the DRV/LSRV benefits using storage is difficult, and attempting to do so by oversizing one's storage system can be costly and outweigh the potential benefits. There will still be value accrued from energy export to the grid from the VDER value stack without DRV/LSRV benefits.

\subsection{Future Studies}

Several opportunities for additional research result from this analysis, especially regarding the impacts of VDER on the solar market. Because of time and resource constraints, we were unable to analyze all facets of the impacts of VDER on solar and storage projects in New York state. A future study could investigate scenarios in which DRV/LSRV values are fully yet economically captured, examine the effect of VDER on single family residential solar and storage projects in NYC, compare the effects of VDER on upstate New York versus NYC, and examine the effects of VDER on community distributed generation (MTC-qualifying) projects. These analyses would provide a clearer picture of the impact of VDER on New York state and help solar developers navigate this unchartered terrain and avoid potentially costly pitfalls.

Longer-term strategic work that could provide additional insights includes developing innovative solutions to scaling the implementation of solar and storage projects in NYC, including:

- Developing strategies for geographically clustering solar and storage projects to leverage investments and reduce the costs associated with grid interconnection through economies of scale

- Incorporating additional technical screens and cost estimates in the NY Solar Map after discussing grid interconnection costs with large-scale solar developers

- Discussing the possibility of a utility alert system when the grid demand is peaking so that local solar project developers can dispatch energy or capacity accordingly and capture the resulting monetary value 
The new VDER framework has opened the door for many new business models, and extensive research could be performed to investigate these new opportunities, looking across both locations and customer classes. 


\section{Appendix A: Detailed Modeling Results}

Table A1. Detailed Results for Scenarios on Rate Tariff SC-8 I (Bold/Italics Indicate Min LCC Solution)

\begin{tabular}{|c|c|c|c|c|c|c|c|c|c|c|}
\hline & & PV Size & PV Orientation & Life Cycle Cost & kWh Exported & kWh Curtailed & Max Export/ Curtailment & Battery Size \\
\hline & & & & kW & degrees & $\$$ & kWh & $\mathrm{kWh}$ & $\mathrm{kW}$ & $\mathrm{kWh} / \mathrm{kW}$ \\
\hline & & & Base case (NEM) & 115 & 180 & $1,873,200$ & 28,400 & 0 & 63 & - \\
\hline & & & Base case (VDER) & 115 & 180 & $1,889,570$ & 28,400 & 0 & 63 & - \\
\hline \multirow{5}{*}{\multicolumn{3}{|c|}{$\begin{array}{l}\frac{t}{0} \\
\stackrel{0}{x} \\
\text { ய } \\
\stackrel{0}{z}\end{array}$}} & PV sizing & 40 & 180 & $2,000,420$ & 0 & 0 & 0 & - \\
\hline & & & $P V$ orientation & 58 & 60 & $2,030,230$ & 0 & 0 & 0 & - \\
\hline & & & PV curtailment & 115 & 180 & $1,968,550$ & 0 & 28,400 & 63 & - \\
\hline & & & Storage & 115 & 180 & $1,760,150$ & 0 & 0 & 0 & $344 / 52$ \\
\hline & & & Combination & 115 & 180 & $1,747,780$ & 0 & 1,307 & 63 & $211 / 39$ \\
\hline \multirow{11}{*}{$\sum_{\mathrm{Z}}$} & \multirow{11}{*}{ 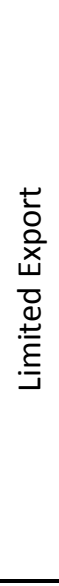 } & \multirow{11}{*}{ 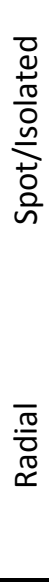 } & PV sizing & 115 & 180 & $1,948,200$ & 28,400 & 0 & 63 & - \\
\hline & & & PV orientation & 115 & 180 & $1,948,200$ & 28,400 & 0 & 63 & - \\
\hline & & & PV curtailment & 115 & 180 & $1,948,200$ & 28,400 & 0 & 63 & - \\
\hline & & & Storage & 115 & 180 & $1,782,220$ & 8,591 & 0 & 61 & $191 / 36$ \\
\hline & & & Combination & 115 & 180 & $1,782,220$ & 8,591 & 0 & 61 & $191 / 36$ \\
\hline & & & & & & & & & & \\
\hline & & & PV sizing & 115 & 180 & $1,888,200$ & 28,400 & 0 & 63 & - \\
\hline & & & PV orientation & 115 & 180 & $1,888,200$ & 28,400 & 0 & 63 & - \\
\hline & & & PV curtailment & 115 & 180 & $1,888,200$ & 28,400 & 0 & 63 & - \\
\hline & & & Storage & 115 & 180 & $1,722,220$ & 8,591 & 0 & 61 & $191 / 36$ \\
\hline & & & Combination & 115 & 180 & $1,722,220$ & 8,591 & 0 & 61 & $191 / 36$ \\
\hline & & & & & & & & & & \\
\hline \multirow{9}{*}{$\begin{array}{l}\stackrel{\mathscr{U}}{\mathrm{D}} \\
\text { }\end{array}$} & \multirow{9}{*}{ 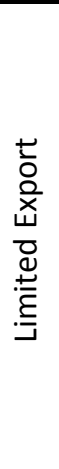 } & \multirow{9}{*}{ 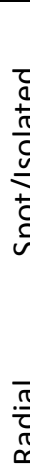 } & PV sizing & 115 & 180 & $1,964,570$ & 28,400 & 0 & 63 & - \\
\hline & & & PV orientation & 115 & 180 & $1,964,570$ & 28,400 & 0 & 63 & - \\
\hline & & & PV curtailment & 115 & 180 & $1,964,570$ & 28,400 & 0 & 63 & - \\
\hline & & & Storage (no ICAP/DRV) & 115 & 180 & $1,785,990$ & 1,951 & 0 & 58 & $198 / 37$ \\
\hline & & & Storage (perfect foresight) & 115 & 180 & $1,699,940$ & 723 & 0 & 53 & $253 / 97$ \\
\hline & & & Combination & 115 & 180 & $1,785,990$ & 1,951 & 0 & 58 & $198 / 37$ \\
\hline & & & & & & & & & & \\
\hline & & & PV sizing & 115 & 180 & $1,904,570$ & 28,400 & 0 & 63 & - \\
\hline & & & PV orientation & 115 & 180 & $1,904,570$ & 28,400 & 0 & 63 & - \\
\hline
\end{tabular}




\begin{tabular}{|c|c|c|c|c|c|c|c|}
\hline & PV Size & PV Orientation & Life Cycle Cost & kWh Exported & kWh Curtailed & Max Export/ Curtailment & Battery Size \\
\hline & kW & degrees & $\$$ & $\mathrm{kWh}$ & $\mathrm{kWh}$ & $\mathrm{kW}$ & kWh/kW \\
\hline Base case (NEM) & 115 & 180 & $1,873,200$ & 28,400 & 0 & 63 & - \\
\hline Base case (VDER) & 115 & 180 & $1,889,570$ & 28,400 & 0 & 63 & - \\
\hline PV curtailment & 115 & 180 & $1,904,570$ & 28,400 & 0 & 63 & - \\
\hline Storage (no ICAP/DRV) & 115 & 180 & $1,725,990$ & 1,951 & 0 & 58 & $198 / 37$ \\
\hline Storage (perfect foresight) & 115 & 180 & $1,639,940$ & 723 & 0 & 53 & $253 / 97$ \\
\hline Combination & 115 & 180 & $1,725,990$ & 1,951 & 0 & 58 & $198 / 37$ \\
\hline
\end{tabular}


Table A2. Detailed Results for Scenarios on Rate Tariff SC-8 II (Bold/Italics Indicate Min LCC Solution)

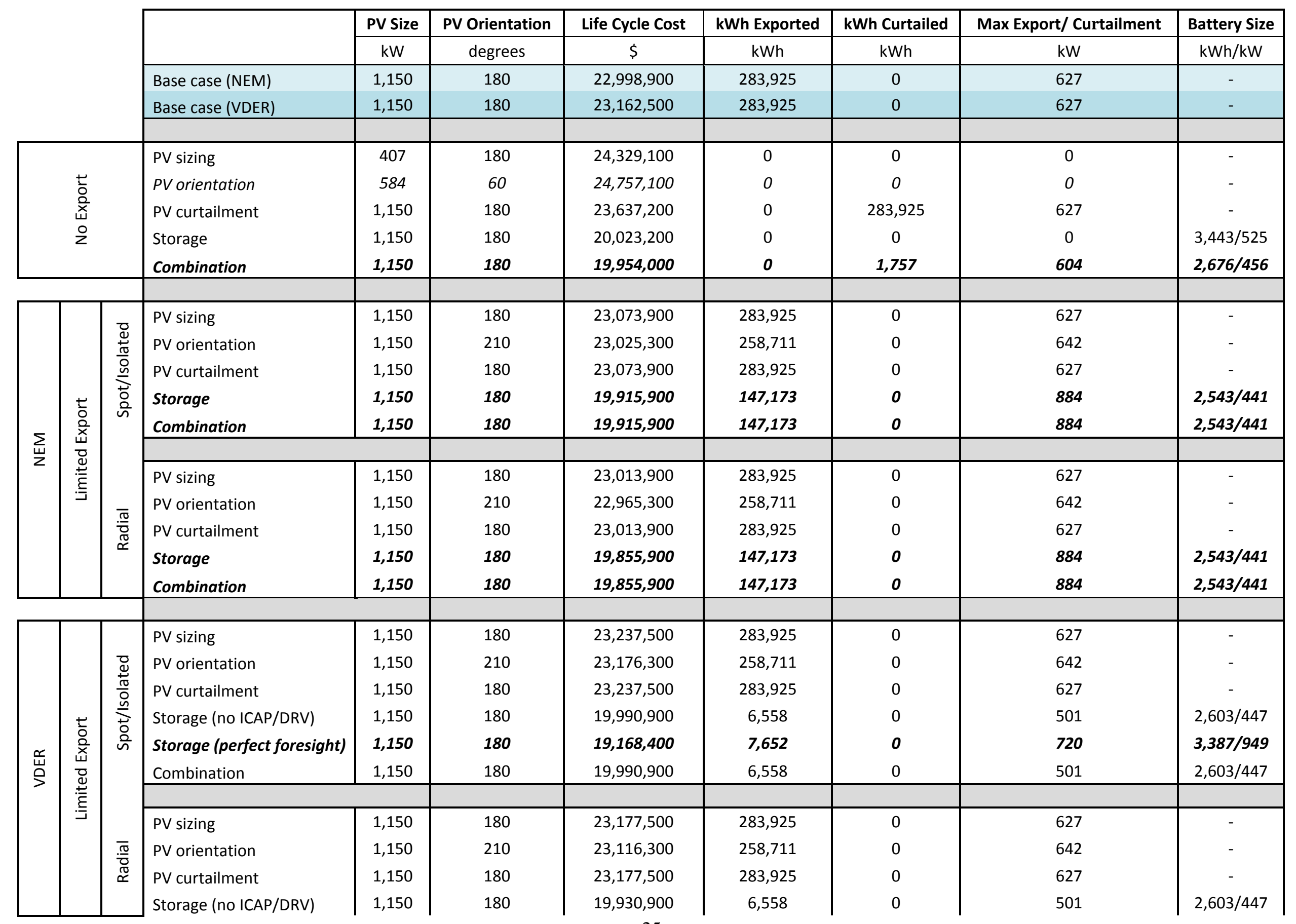




\begin{tabular}{|c|c|c|c|c|c|c|c|}
\hline & PV Size & PV Orientation & Life Cycle Cost & kWh Exported & kWh Curtailed & Max Export/ Curtailment & Battery Size \\
\hline & kW & degrees & $\$$ & $\mathrm{kWh}$ & kWh & $\mathrm{kW}$ & $\mathrm{kWh} / \mathrm{kW}$ \\
\hline Base case (NEM) & 1,150 & 180 & $22,998,900$ & 283,925 & 0 & 627 & - \\
\hline Base case (VDER) & 1,150 & 180 & $23,162,500$ & 283,925 & 0 & 627 & - \\
\hline Storage (perfect foresight) & 1,150 & 180 & $19,108,400$ & 7,652 & 0 & 720 & $3,387 / 949$ \\
\hline Combination & 1,150 & 180 & $19,930,900$ & 6,558 & 0 & 501 & $2,603 / 447$ \\
\hline
\end{tabular}


Table A3. Detailed Results for Scenarios on Rate Tariff SC-9 I (Bold/Italics Indicate Min LCC Solution)

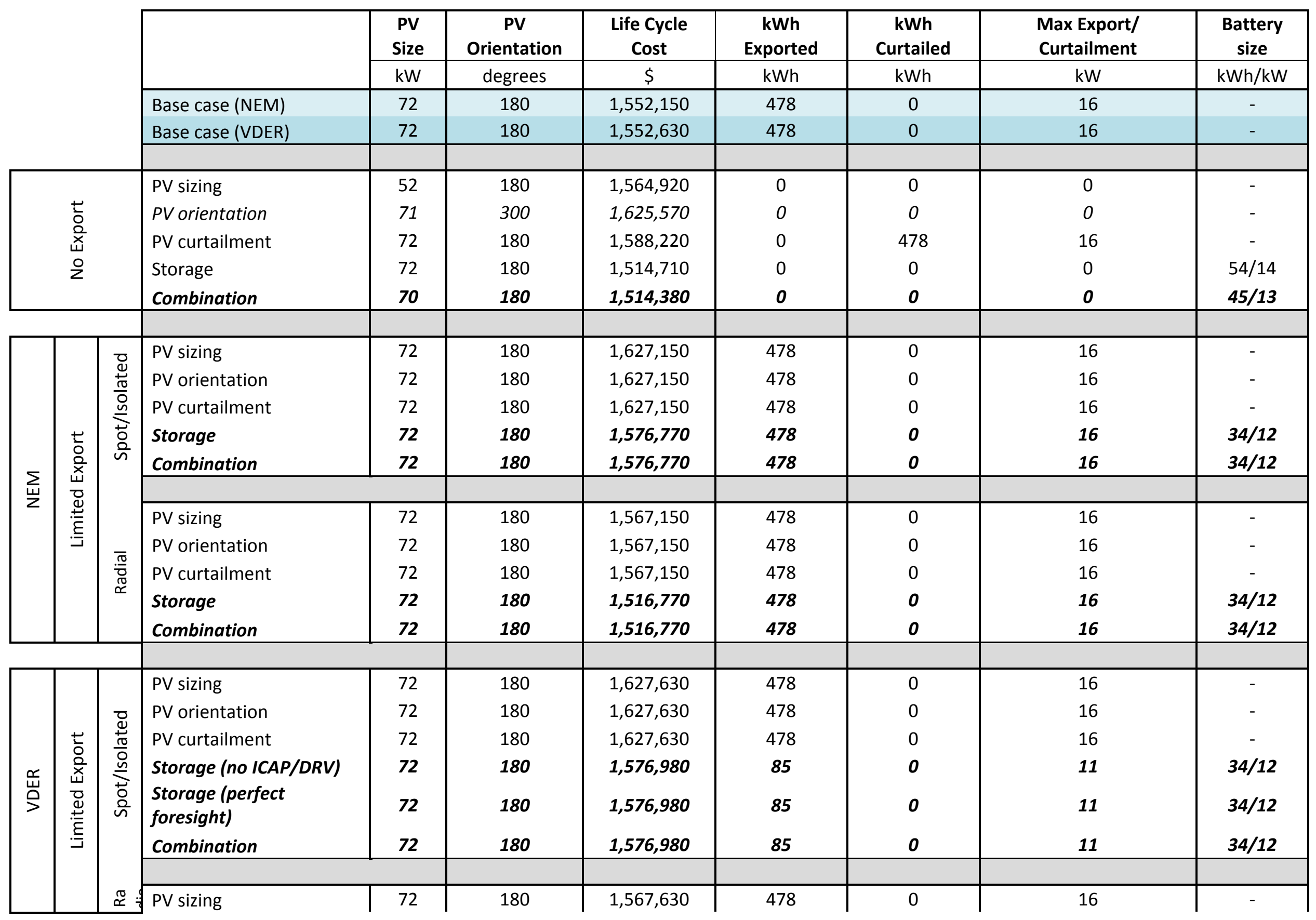




\begin{tabular}{|c|c|c|c|c|c|c|c|}
\hline & $\begin{array}{l}\text { PV } \\
\text { Size }\end{array}$ & $\begin{array}{c}\mathrm{PV} \\
\text { Orientation }\end{array}$ & $\begin{array}{l}\text { Life Cycle } \\
\text { Cost }\end{array}$ & $\begin{array}{c}\text { kWh } \\
\text { Exported }\end{array}$ & $\begin{array}{l}\text { kWh } \\
\text { Curtailed }\end{array}$ & $\begin{array}{l}\text { Max Export/ } \\
\text { Curtailment }\end{array}$ & $\begin{array}{l}\text { Battery } \\
\text { size }\end{array}$ \\
\hline & $\mathrm{kW}$ & degrees & $\$$ & $\mathrm{kWh}$ & $\mathrm{kWh}$ & kW & $\mathrm{kWh} / \mathrm{kW}$ \\
\hline Base case (NEM) & 72 & 180 & $1,552,150$ & 478 & 0 & 16 & - \\
\hline Base case (VDER) & 72 & 180 & $1,552,630$ & 478 & 0 & 16 & - \\
\hline PV orientation & 72 & 180 & $1,567,630$ & 478 & 0 & 16 & - \\
\hline PV curtailment & 72 & 180 & $1,567,630$ & 478 & 0 & 16 & - \\
\hline Storage (no ICAP/DRV) & 72 & 180 & $1,516,980$ & 85 & 0 & 11 & $34 / 12$ \\
\hline $\begin{array}{l}\text { Storage (perfect } \\
\text { foresight) }\end{array}$ & 72 & 180 & $1,516,980$ & 85 & 0 & 11 & 34/12 \\
\hline Combination & 72 & 180 & $1,516,980$ & 85 & 0 & 11 & $34 / 12$ \\
\hline
\end{tabular}


Table A4. Detailed Results for Scenarios on Rate Tariff SC-9 II (Bold/Italics Indicate Min LCC Solution)

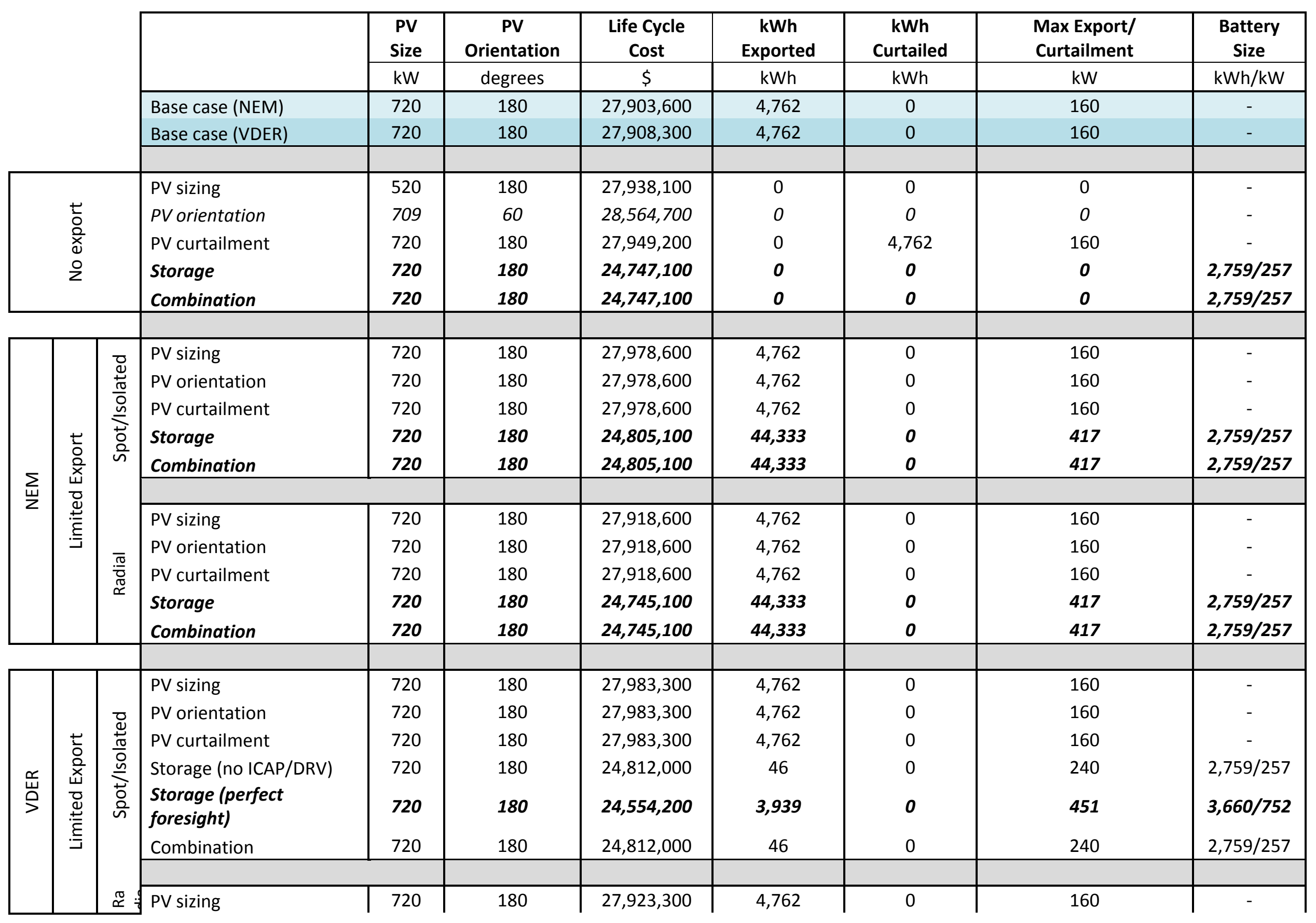




\begin{tabular}{|c|c|c|c|c|c|c|c|}
\hline & $\begin{array}{l}\text { PV } \\
\text { Size }\end{array}$ & $\begin{array}{c}\mathrm{PV} \\
\text { Orientation }\end{array}$ & $\begin{array}{l}\text { Life Cycle } \\
\text { Cost }\end{array}$ & $\begin{array}{l}\text { kWh } \\
\text { Exported }\end{array}$ & $\begin{array}{l}\text { kWh } \\
\text { Curtailed }\end{array}$ & $\begin{array}{l}\text { Max Export/ } \\
\text { Curtailment }\end{array}$ & $\begin{array}{l}\text { Battery } \\
\text { Size }\end{array}$ \\
\hline & $\mathrm{kW}$ & degrees & $\$$ & $\mathrm{kWh}$ & $\mathrm{kWh}$ & kW & $\mathrm{kWh} / \mathrm{kW}$ \\
\hline Base case (NEM) & 720 & 180 & $27,903,600$ & 4,762 & 0 & 160 & - \\
\hline Base case (VDER) & 720 & 180 & $27,908,300$ & 4,762 & 0 & 160 & - \\
\hline PV orientation & 720 & 180 & $27,923,300$ & 4,762 & 0 & 160 & - \\
\hline PV curtailment & 720 & 180 & $27,923,300$ & 4,762 & 0 & 160 & - \\
\hline Storage (no ICAP/DRV) & 720 & 180 & $24,752,000$ & 46 & 0 & 46 & $2,759 / 257$ \\
\hline $\begin{array}{l}\text { Storage (perfect } \\
\text { foresight) }\end{array}$ & 720 & 180 & $24,494,200$ & 3,939 & 0 & 451 & $3,660 / 752$ \\
\hline Combination & 720 & 180 & $24,752,000$ & 46 & 0 & 46 & $2,759 / 257$ \\
\hline
\end{tabular}




\section{Appendix B: REopt Characteristics and Module Constraints}

A qualitative overview of the components of the objective function as well as the main constraint categories within REopt are given here. Formulated as a mixed-integer linear program, REopt solves a deterministic optimization problem to determine the optimal selection, sizing, and dispatch strategy of technologies chosen from a candidate pool such that electrical and thermal loads are met at every time step at the minimum life cycle cost.

\section{Objective Function}

The objective function of the mixed-integer linear program is to minimize the present value of all energy costs incurred during the analysis period including:

- Capital costs: Investments made to acquire new energy generation capacity, storage units, and other auxiliary equipment

- Operating expenses: Fixed and variable technology operation and maintenance costs, equipment replacement costs, fuel costs, utility purchases, and financial losses that are incurred due to grid outages

- Operating revenues: Net metering income, wholesale electricity sales, and production-based incentives

- Incentives and tax benefits: Federal, state, and utility incentives, and accelerated depreciation schedules

- Cash flows: Costs found during the analysis period by first escalating present costs at projectspecific inflation and utility cost escalation rates, and then discounting back to the present using a client-determined discount rate.

\section{Constraints}

The constraints governing how REopt builds and dispatches technologies fall into the following categories:

- Load constraints: Loads must be fully met by some combination of renewable and conventional generation during every time step. Typically, hourly or 15-minute time steps are used in the model. Additional load constraints restrict the amount of energy that a technology can replace.

- Resource constraints: The amount of energy that a technology can produce is limited by the amount of resources available within a region or by the size of the fuel storage systems. The energy production of variable technologies is limited by the renewable resource at the location, while the utility grid is assumed to be able to provide unlimited amounts of energy.

- Operating constraints: Dispatchable technologies may have minimum turndown limits that prevent them from operating at partial loads less than a specified level. Other operating constraints may limit the number of times a dispatchable technology can cycle on and off each day or impose minimum and maximum state of charge requirements on battery technology. 
- $\quad$ Sizing constraints: Most sites have limited land and roof area available for renewable energy installations, which may restrict the sizes of technologies like PV. The client may also specify acceptable minimum and maximum technology sizes as model inputs.

- Policy constraints: Utilities often impose limits on the cumulative amount of renewable generation a site can install and still qualify for a net metering agreement. Other policy constraints may restrict the size of a variable technology system for it to be eligible for a production incentive.

- Scenario constraints (optional): Constraints may require a site to achieve some measure of energy resiliency by meeting the critical load for a defined period with on-site generation assets.

\section{Temporal Resolution}

REopt uses time series integration to combine the energy production from concurrently operating technologies. The optimization model assumes production and consumption are constant across all years of analysis, and so only considers the energy balance of Year 1. The typical time step is one hour, which results in 8,760 time steps in a typical $\mathrm{N}$-year analysis. This ensures seasonal variations in load and resource availability are captured.

\section{Resource Data}

REopt automatically queries NREL's geographic information system databases to gather renewable energy resource data. This information is used to calculate the production profiles of various technologies. REopt uses hourly solar irradiance values from TMY2 data from the 1991-2005 National Solar Radiation Database. ${ }^{23}$

\section{Incentives}

REopt considers available federal, state, and local incentives, including cost-based incentives, productionbased incentives, and tax incentives. Cost-based incentives are modeled in units of dollars per kilowatt or percentage of installed cost, and a maximum total incentive value and maximum system size may be specified. Production-based incentives are modeled in units of dollars per kilowatt-hour generated per year, given the number of years for which the incentive is available. A maximum incentive value per year and system size may be specified. Net metering benefits are also considered.

\section{Rate Tariffs}

REopt supports complex tariff structures that include both peak demand charges and time-of-use consumption rates. Demand rates may be specified for on-peak and off-peak hours, which can vary by season. Time-of-use consumption rates may vary by the time of day, the season, or both.

\section{Economic Modeling}

The economic cost-benefit analysis within REopt is based on general economic theory. The approach and terminology are based on the Manual for the Economic Evaluation of Energy Efficiency and Renewable

\footnotetext{
${ }^{23}$ Wilcox, S. (2007). “National Solar Radiation Database 1991-2005 Update: User’s Manual.” http://www.osti.gov/energycitations/product.biblio.jsp?osti_id=901864
} 
Energy Technologies, ${ }^{24}$ and they abide by the life cycle cost methods and criteria for federal energy projects as described in the "Federal Code of Regulations 10 CFR Part 436 - Subpart A," and which are detailed in "NIST Handbook 135, Life-Cycle Costing Manual for the Federal Energy Management Program." 25

\section{PV Model}

REopt uses NREL's PVWatts Calculator application to determine the electricity production of installed PV systems. The amount of electricity produced by the PV array at each time step is proportional to the hourly capacity factor at the site. Because the production of a PV arrays tends to decline over its lifespan, and the model only optimizes over one year, REopt calculates an annual production profile that has an economic equivalent production profile with $0.5 \% /$ year degradation over the analysis period. The economic equivalent profile is calculated by applying the ratio of geometric series present worth factor (with degradation included) and uniform series present worth factor to the local production profile.

Refer to the PVWatts technical reference manual ${ }^{26}$ for further modeling assumptions and descriptions.

\section{Battery Modeling}

Energy storage is modeled as a "reservoir" in REopt, where energy produced during one time step can be consumed during another. REopt does not explicitly model battery chemistries, but rather, it imposes heuristic constraints that are designed to ensure the battery operates within the manufacturer's specifications. A round-trip efficiency is assumed, and limits are imposed on the minimum state of charge, charging and discharging rates, and the number of cycles per day. The model can select and size both the capacity of the battery in kilowatt-hours and the power delivery in kilowatts. By default, any technology can charge the energy storage device, but charging can also be limited to specific technologies.

\footnotetext{
${ }^{24}$ Short, Walter, Daniel J. Packey, and Thomas Holt (1995). “A Manual for the Economic Evaluation of Energy Efficiency and Renewable Energy Technologies.” http://www.nrel.gov/docs/legosti/old/5173.pdf.

${ }^{25}$ Fuller, Sieglinde K., and Stephen R. Petersen (1995). "Life-Cycle Costing Manual for the Federal Energy Management Program.” http://fire.nist.gov/bfrlpubs/build96/PDF/b96121.pdf.

${ }^{26}$ Dobos, Aron P. (2014). “PVWatts Version 5 Manual.” http://www.nrel.gov/docs/fy14osti/62641.pdf.
} 


\section{Appendix C: Analysis Assumptions}

\section{Building Load}

The building type that most closely matched the data provided by Con Edison was selected to simulate one year of hourly load. The commercial reference building load profiles were then scaled to match the average annual consumption expected under each rate structure. The closest matching building type and its average demand are given for each rate in the Table $\mathbf{A 5 .}$

Table A5. Insert Table Caption Here

\begin{tabular}{|l|c|c|}
\hline & $\begin{array}{c}\text { Average Demand } \\
(\mathbf{k W})\end{array}$ & Commercial Reference Building Type \\
\hline SC-8 I & 50 & midrise apartment \\
\hline SC-8 II & 500 & hospital \\
\hline SC-9 I & 50 & \\
\hline SC-9 II & 500 & \\
\hline
\end{tabular}

\section{PV Costs}

To obtain a fair comparison of all the mitigation strategies, installed PV costs were adjusted to be at the break-even point at which the desired system size just becomes cost-effective. They are the highest possible PV costs at which the maximum PV size is still economical to build. These costs, shown in Table A6, do not account for available incentives. These costs may not be representative of actual PV costs in NYC, as the focus of this analysis is to compare mitigation strategies for large scale PV and not to study the economic viability of PV in New York.

Table A6. Insert Table Caption Here

\begin{tabular}{|l|c|c|}
\hline & PV Size (kW) & PV Cost (\$/W) \\
\hline SC-8 I & 115 & 1.59 \\
\hline SC-8 II & 1,150 & 1.99 \\
\hline SC-9 I & 72 & 2.98 \\
\hline SC-9 II & 720 & 3.40 \\
\hline
\end{tabular}

